This document is the accepted manuscript version of the following article:

Chen, B., Hu, J. N., Wang, Y. Q., Zhang, S. Y., Van Petegem, S., Cocks, A. C. F., ... Flewitt, P. E. J. (2015). Role of the misfit stress between grains in the Bauschinger effect for a polycrystalline material. Acta Materialia, 85, 229-242. https://doi.org/10.1016/j.actamat.2014.11.021

This manuscript version is made available under the CC-BY-NC-ND 4.0 1icense http://creativecommons.org/1icenses/by-nc-nd/4.0/

\title{
Role of the Misfit Stress between Grains on the Bauschinger Effect for a Polycrystalline Material
}

\author{
B. Chen ${ }^{1, a,{ }^{*}}$, J.N. Hu ${ }^{\text {b }}$ Y.Q. Wang ${ }^{\mathrm{a}}$, S.Y. Zhang ${ }^{\mathrm{c}}$, S. Van Petegem ${ }^{\mathrm{d}}$, A.C.F. Cocks ${ }^{\mathrm{b}}$, \\ D.J. Smith ${ }^{\mathrm{a}}$, P.E.J. Flewitt ${ }^{\mathrm{e}}$ \\ ${ }^{a}$ Department of Mechanical Engineering, University of Bristol, Bristol, BS8 1TR, UK \\ ${ }^{b}$ Department of Engineering Science, University of Oxford, OX1 3PJ, UK \\ ${ }^{c}$ ISIS, Science and Technology Facilities Council, Rutherford Appleton Laboratory, Chilton, Didcot, \\ Oxfordshire, OX11 OQX,UK \\ ${ }^{d}$ Material Science and Simulations, Paul Scherrer Institut, CH-5232 Villigen, Switzerland \\ ${ }^{e}$ H.H. Wills Physics Laboratory, University of Bristol, Tyndall Avenue, Bristol, BS8 1TL, UK \\ *Corresponding author. Tel.: +44 117331 5941. Fax: +44 1179294423. \\ E-mail address: bo.chen-2@manchester.ac.uk
}

\begin{abstract}
The role of misfit stress on kinematic hardening under reversed straining of a Type $316 \mathrm{H}$ austenitic stainless steel has been investigated by using the neutron diffraction technique combined with in-situ deformation. Initial misfit stresses, often referred to an intergranular internal stresses, were created by the tensile pre-straining at high temperature. The misfit stresses at the length-scale of grain families, measured by neutron diffraction, were shown to be a function of the magnitude of the tensile prestrain. The pre-strained specimens were further subjected to either continued (tensile) straining or reversed (compressive) straining at room temperature. In-situ neutron diffraction measurements were undertaken to monitor the change of the misfit stresses during loading. The macroscopic stress-strain behaviour was used to derive isotropic and kinematic hardening stresses developed in the pre-strained specimens. Results show that the change of the transient softening stress towards a zero value is accompanied by a decrease in the change of the misfit stresses. A multi-scale selfconsistent model has been developed to assist in understanding the measured change of the misfit stresses when subjecting the material to strain reversal. An important conclusion is that the origin of the kinematic hardening of Type $316 \mathrm{H}$ austenitic stainless steel arises from the misfit stress between grains.
\end{abstract}

Keywords: Internal stress; Neutron diffraction; Crystal plasticity; Bauschinger effect; Creep; Polycrystalline material

\footnotetext{
${ }^{1}$ Present address: Materials Performance Centre, School of Materials, The University of Manchester, Manchester, M13 9PL
} 


\section{Nomenclature}

\begin{tabular}{|l|l|}
\hline$d_{h k l}$ & Lattice spacing for a $\{h k l\}$ grain family under a stressed condition \\
\hline$d_{h k l}^{0}$ & Stress free lattice spacing for a $\{h k l\}$ grain family \\
\hline$E_{h k l}$ & Diffraction elastic constant for a $\{h k l\}$ grain family \\
\hline$T$ & Temperature \\
\hline$v$ & Poisson's ratio \\
\hline$\varepsilon_{o f f}$ & A small strain offset used to determine the transient softening stress \\
\hline$\varepsilon_{h k l}$ & Misfit strain for a $\{h k l\}$ grain family \\
\hline$\varepsilon_{h k l}^{z z}$ & Axial misfit strain for a $\{h k l\}$ grain family \\
\hline$\varepsilon_{h k l}^{\theta \theta}$ & Hoop misfit strain for a $\{h k l\}$ grain family \\
\hline$\varepsilon_{h k l}^{r r}$ & Radial misfit strain for a $\{h k l\}$ grain family \\
\hline$\dot{\varepsilon}_{i n}$ & Inelastic strain rate \\
\hline$\Delta \varepsilon_{h k l}^{z z}$ & $\begin{array}{l}\text { Elastic lattice strain difference between the measurements undertaken at in-situ } \\
\text { tensile and compressive deformation for a }\{h k l\} \text { grain family }\end{array}$ \\
\hline$\sigma_{0}$ & $\begin{array}{l}\text { Initial yield stress describing an isotropic resistance to create inelastic flow of } \\
\text { material }\end{array}$ \\
\hline$\sigma_{a}$ & Applied stress \\
\hline$\sigma_{f}$ & Flow stress obtained at continued straining \\
\hline$\sigma_{r}$ & $\begin{array}{l}\text { Flow stress obtained at reverse } \\
\text { d straining }\end{array}$ \\
\hline$\sigma_{p s}$ & Permanent softening stress \\
\hline$\sigma_{t s}$ & Transient softening stress \\
\hline$\sigma_{f 0}$ & $\begin{array}{l}\text { Continued straining flow stress used to determine the magnitude of transient } \\
\text { softening }\end{array}$ \\
\hline$\sigma_{r 0}$ & $\begin{array}{l}\text { Reversed straining flow stress used to determine the magnitude of transient } \\
\text { softening }\end{array}$ \\
\hline$\sigma_{k}$ & Stress representing the isotropic hardening component created by pre-strain \\
\hline$\sigma_{\alpha}$ & Stress representing the kinematic hardening component created by pre-strain \\
\hline$\sigma_{h k l}^{z z}$ & Axial misfit stress for a $\{h k l\}$ grain family \\
\hline & \\
\hline
\end{tabular}

\section{Introduction}

There has been extensive research on the development of constitutive models to describe the inelastic deformation of polycrystalline materials when subjected to high temperature loading [1-3]. In particular, the inelastic deformation of metals is known to be sensitive to the strain path. One simple way to change the strain path is to reverse the direction of deformation [4]. If a pre-strained material is stressed in the direction opposite to that of the pre-strain direction, a lower yield strength is often obtained and this causes the inelastic material flow at a lower applied stress. This is 
called the Bauschinger effect [5] and is shown schematically in Figure 1. This figure is a simplified representation of results explained later in the paper. For example, the curve $\mathrm{OABC}$ represents the high temperature deformation for an austenitic stainless steel specimen and the curve CO' when it is unloaded. Subsequent loading in tension at room temperature gives rise to curve $\mathrm{O}^{\prime} \mathrm{CDEF}$, while compressive loading leads to deformation given by curve O'GHI. Inverting this curve gives rise to the dotted line O'G'H'I' that now lies below the curve O'CDEF. This phenomenon has been regarded as important for revealing an intrinsic feature of the strain hardening process [6], and therefore has been employed for many years to refine both continuum and dislocation based microstructural theories to describe strain hardening [7, 8].

The Bauschinger effect is characterised by two distinct stress-strain phenomena; transient and permanent softening stresses which relate to the magnitudes of $\sigma_{t s}$ and $\sigma_{p s}$ as indicated in Figure 1. These two stresses are determined by comparing the tensile curve O'DEF with the curve O'G'H'I'. The influence of high temperature prestraining on subsequent yield strength asymmetry observed in room temperature Bauschinger effect tests has been experimentally confirmed [9]. The small strain offset, $\varepsilon_{o f f}$, is often used to determine the point $\mathrm{H}$ (and hence $\mathrm{H}^{\prime}$ ) on the compressive curve. The magnitude of the transient softening stress, $\sigma_{t s}$, is evaluated from the difference between the continued straining flow stress, $\sigma_{f 0}$ (point E) and the reversed straining flow stress, $\left|\sigma_{r 0}\right|$ (point $\mathrm{H}^{\prime}$ ) in Figure 1. A large strain offset captures the behaviour of permanent softening, as depicted by the stress $\sigma_{p s}$ in Figure 1. This stress is calculated from the difference between the values for the flow stress at continued straining and at reversed straining, $\sigma_{f}-\left|\sigma_{r}\right|$, defined by points $\mathrm{F}$ and I' in Figure 1.

In previous work $[10,11]$ transmission electron microscopy (TEM) was performed at different stages of the transient process upon strain reversal to explore the evolution of the dislocation density and arrangement. The dislocation arrangement associated with the transient softening could arise from features such as sub-structure disintegration, back flow of the piled-up dislocations, and dislocation interactions with solute atoms and/or second phase precipitates. However, Rauch et al. [12] showed that the relationship between the evolution of the dislocations and the transient softening upon strain reversal is not unique.

Recent advances in modelling inelastic behaviour include the introduction of internal state variables [13]. In general, three variables have been considered to 
describe the evolution of inelastic deformation [14]: (i) an initial yield stress, $\sigma_{0}$, describing an isotropic resistance to create inelastic flow of material; (ii) a stress, $\sigma_{\kappa}$, describing a sum of contributions from isotropic hardening; and (iii) a stress, $\sigma_{\alpha}$, that contributes to kinematic hardening. In general, the inelastic strain rate, $\dot{\varepsilon}_{i n}$, is a function of applied and internal variables:

$$
\dot{\varepsilon}_{i n}=f\left(\sigma_{a}, T, \sigma_{0}, \sigma_{\kappa}, \sigma_{\alpha}\right)
$$

where $\sigma_{a}$ is the applied stress and $T$ is the temperature. By characterising the evolution of both the terms $\sigma_{\kappa}$ and $\sigma_{\alpha}$, the response of material under various loading conditions can be modelled.

The initial yield stress $\sigma_{0}$ corresponds to point D in Figure 1. The magnitude of $\sigma_{0}$ is temperature dependent and for the conditions considered in this paper point $\mathrm{D}$ exceeds point $\mathrm{C}$. The elevation of the yield strength at room temperature can be attributed to the contribution from the presence of solid solution elements $[15,16]$ as well as the temperature dependence of Young's modulus $[17,18]$. Both the isotropic and kinematic hardening components contribute to the strain hardening of a material and the flow stress, $\sigma_{f}$, can be expressed as:

$$
\sigma_{f}=\sigma_{0}+\sigma_{\kappa}+\sigma_{\alpha}
$$

where $\sigma_{f}$ acts in the same direction as the high temperature pre-strain, Figure 1. $\sigma_{\kappa}$ and $\sigma_{\alpha}$ represent the isotropic and the kinematic hardening components created by prestrain. If the material is subjected to a reversed straining after the tensile pre-strain, the flow stress during compressive straining, $\sigma_{r}$, is given by:

$$
\sigma_{r}=-\sigma_{0}-\sigma_{\kappa}+\sigma_{\alpha}
$$

Combining equations 2 and 3 , the isotropic and kinematic hardening stresses are given by:

$$
\sigma_{\kappa}=\frac{\sigma_{f 0}-\sigma_{r 0}}{2}-\sigma_{0}
$$




$$
\sigma_{\alpha}=\frac{\sigma_{f 0}+\sigma_{r 0}}{2}
$$

All three parameters $\sigma_{0}, \sigma_{f 0}, \sigma_{r 0}$, can be measured from Bauschinger effect tests, as shown by points D, E and H (or H') in Figure 1. The gradual change in the magnitude of $\sigma_{t s}$ to that of $\sigma_{p s}$ is associated with the change in the strain hardening arising from both isotropic hardening and kinematic hardening components. Thus the main modelling challenge lies in constructing an accurate evolution equation for each term ( $\sigma_{\kappa}$ and $\left.\sigma_{\alpha}\right)$, [19]. A change in the magnitude of each term could occur during reversed straining [14]. In a series of uniaxial experiments on face-centred-cubic (FCC) polycrystalline copper, undertaken by Miller et al. [19], both stresses $\sigma_{\kappa}$ and $\sigma_{\alpha}$ were measured using interrupted test data at various levels of pre-strains up to $30 \%$. However, the evolutions of the stresses during either tensile or reversed straining were not considered. This was limited by the ex-situ feature of mechanically based Bauschinger effect tests. Therefore there is an incomplete understanding of the meaning of the magnitudes of the transient $\left(\sigma_{t s}\right)$ and permanent softening $\left(\sigma_{p s}\right)$ stresses.

In the present paper, we report an experimental study of the Bauschinger effect observed in a Type $316 \mathrm{H}$ austenitic stainless steel. This was undertaken by combining neutron diffraction strain/stress measurements with in-situ tension and compression tests. The magnitudes of the misfit stresses between grains, also referred to intergranular internal stresses [20], created by high temperature pre-straining were measured together with the evolution of these stresses during in-situ tests. The measured results were compared with the predictions based on a multi-scale selfconsistent model. Finally, the Bauschinger effect observed in the macroscopic tests can be correlated with the misfit stresses between grains.

\section{Material and Experimental}

Experiments were undertaken in two stages; first Type $316 \mathrm{H}$ austenitic stainless steel specimens were pre-strained at $550{ }^{\circ} \mathrm{C}$ and then cooled under the applied load and finally unloaded at room temperature. Second, the specimens were then taken to two neutron diffraction facilities and subjected to either in-situ incremental tension or compression testing at room temperature. This section describes the material, specimens and experimental methods. 


\subsection{Material}

The material used for this study was a Type $316 \mathrm{H}$ austenitic stainless steel, with a chemical composition given in Table 1. The material, supplied by EDF Energy plc., was extracted from components that had experienced in-service exposure, which included $65,015 \mathrm{~h}$ operation at temperatures between $490{ }^{\circ} \mathrm{C}$ to $530{ }^{\circ} \mathrm{C}$. The exservice components were then exposed to further thermal ageing at $550{ }^{\circ} \mathrm{C}$ for 22,100 h. Using the linear intercept method the grain size for this material was measured to be $87 \pm 9 \mu \mathrm{m}$ and both inter- and intra-granular $\mathrm{M}_{23} \mathrm{C}_{6}$ carbide precipitates were present in this thermally aged material [21]. Typical diameters of these inter- and intragranular precipitates were measured to be $0.2 \mu \mathrm{m}$ and $0.03 \mu \mathrm{m}$, respectively. Since the sizes of precipitates are small, the material is judged to be essentially a single phase, FCC polycrystalline stainless steel.

\subsection{High temperature tensile pre-straining}

Uniaxial round bar specimens with a $28.25 \mathrm{~mm}$ gauge length and $5.65 \mathrm{~mm}$ diameter were manufactured from the Type $316 \mathrm{H}$ stainless steel. In total 9 specimens were tested, with the conditions summarised in Table 2. With the exception of two tests, reference specimens 1 and 6 , all tests were undertaken at $550{ }^{\circ} \mathrm{C}$ and a maximum engineering stress of $250 \mathrm{MPa}$ using load controlled creep rigs. Two linear variable differential transducers (LVDTs) were used to measure the elongation of each specimen during initial loading and during constant load creep.

Four pre-strain conditions were considered: (i) loaded to an engineering stress of $250 \mathrm{MPa}$, cooled to room temperature (specimens 2 and 7) and unloaded elastically and (ii), (iii) and (iv) loaded to an engineering stress of 250MPa and allowed to creep for $160 \mathrm{~h}$ (specimens 3 and 8), $720 \mathrm{~h}$ (specimen 4) and $1000 \mathrm{~h}$ (specimens 5 and 9) respectively. Again the specimens were cooled to room temperature and unloaded elastically. The tests crept for $160 \mathrm{~h}$ were terminated during primary creep, while for the longer duration tests specimens achieved secondary creep. Figure 1 shows schematically the high temperature pre-straining conditions, curve OABC. Point A represents the condition for simple loading alone where only elastic-plastic deformation had occurred. Point B is the condition corresponding to primary creep 
and point $\mathrm{C}$ the condition corresponding to secondary creep. The measured plastic loading and creep inelastic strains are shown in Table 2.

These tensile pre-strained specimens as well as the reference specimens 1 and 6 , shown in Table 2, were then subjected to in-situ deformation combined with neutron diffraction measurements. For the in-situ compressive deformation, cylindrical specimens, $10 \mathrm{~mm}$ long, were prepared from the uniformly deformed gauge length of the pre-strained specimens. Thus diameters of the compressive specimens 1 to 4 depended on the level of the tensile pre-strain at high temperature, Table 2. For the in-situ tensile deformation, specimens 5 to 9 had the same geometry to those subjected to the pre-strain, Table 2. More details for the in-situ deformation will be given in section 2.4 .

\subsection{Measurement of misfit strains and stresses}

It has been recognised that the misfit strains/stresses are dependent on crystallographic orientation of the surrounding grains [20]. Misfit strains between grains in the pre-strained specimens were evaluated from the relative change of their lattice spacings. When undertaking neutron diffraction measurements, the lattice spacing for a family of $\{h k l\}$ grains oriented for diffraction is measured. Hence the lattice strain, referred to as the misfit strain, is the average for many $\{h k l\}$ grains oriented for diffraction.

Neutron diffraction instruments at both the ENGIN-X, ISIS in the UK and the POLDI, PSI in Switzerland, were used, Table 2. These two instruments have been described elsewhere [22-25], and there are some important differences between them to be noted. The ENGIN-X diffractometer is based on the concept of time-of-flight of a pulsed polychromatic beam of neutrons, thus many diffraction peaks corresponding to different families of $\{h k l\}$ grains can be measured simultaneously [23]. The POLDI diffractometer uses the multiple pulse-overlap of a continuous spallation neutron source $[24,25]$. A multi-slit chopper intentionally allows multiple frame overlap. Both the time and angular information of the neutrons are recorded. As a result, the POLDI instrument also provides a measure of multiple diffraction peaks corresponding to different grain families.

From measurements of lattice spacing and knowing the stress free lattice spacing, 
the misfit strain, $\varepsilon_{h k l}$ for the $\{h k l\}$ grain family, can be determined using:

$$
\varepsilon_{h k l}=\frac{d_{h k l}-d_{h k l}^{0}}{d_{h k l}^{0}}
$$

where $\mathrm{d}_{\mathrm{hkl}}$ is the lattice spacing under a stressed condition and $d_{h k l}^{0}$ is the stress free lattice spacing. In the present work, four grain families were measured: $\{111\},\{200\}$, $\{220\}$ and $\{311\}$. Specimens 1 and 6 (Table 2) provided a reference condition since they had not been subjected to high temperature pre-straining. Nonetheless the specimens were created from ex-service material. The lattice spacings measured in specimens 2 to 5 and 7 to 9 , Table 2, were then compared with those measured in specimens 1 and 6 , respectively. This provided a measure of misfit strain introduced to the pre-strained specimens.

Measurements of lattice spacing using the ENGIN-X instrument adopted a $3 \mathrm{~mm} \times$ $3 \mathrm{~mm} \times 4 \mathrm{~mm}$ gauge volume. A typical measurement time of $540 \mathrm{~s}$ was selected to ensure good counting statistics for the diffraction peaks. A single peak fitting routine, available at ENGIN-X, was used to determine specific lattice spacings [23]. Also a macroscopic misfit strain was estimated from a Rietveld refinement analysis of the complete diffraction spectrum [26]. For the POLDI measurements, a larger $4 \mathrm{~mm} \times 4$ $\mathrm{mm} \times 6 \mathrm{~mm}$ gauge volume was used and the sampling time for each measurement was $1800 \mathrm{~s}$. A Gaussian function single peak fitting was used to determine the lattice spacing [27].

The arrangement of the specimens in the two instruments is shown in Figure 2. One detector was fitted in the POLDI instrument, and this was arranged to measure the axial strain, Figure 2 (a). In the ENGIN-X instrument the two detectors measured both the axial and radial strains, as shown in Figure 2 (b). When the principal strain directions are known, three measurement orientations are sufficient and the strain vectors measured by neutron diffraction can be converted to stress by the generalised Hooke's law:

$$
\sigma_{h k l}^{z z}=\frac{E_{h k l}}{1+v} \varepsilon_{h k l}^{z z}+\frac{E_{h k l} v}{(1+v)(1-2 v)}\left(\varepsilon_{h k l}^{z z}+\varepsilon_{h k l}^{\theta \theta}+\varepsilon_{h k l}^{r r}\right)
$$


where $\sigma_{h k l}^{z z}$ is the axial misfit stress, $E_{h k l}$ is the diffraction elastic constant for a specific $\{h k l\}$ grain family and $v$ is the Poisson's ratio $(v=0.29) . \varepsilon_{h k l}^{z z}, \varepsilon_{h k l}^{\theta \theta}$ and $\varepsilon_{h k l}^{r r}$ are axial, hoop and radial misfit strains, where the three superscripts, $z z, \theta \theta$ and $r r$, are three principal directions in the cylindrical coordinate system.

In both instruments the strain state at the centre of the specimen was measured and therefore the measured misfit strain along the radial direction was assumed equal to that along the hoop direction $\left(\varepsilon_{h k l}^{r r}=\varepsilon_{h k l}^{\theta \theta}\right)$. In the ENGIN-X instrument both axial and radial strains were measured. In contrast only the axial strain was measured and the axial stress was calculated assuming the radial strain, $\varepsilon_{h k l}^{r r}$, was equal to $-v \varepsilon_{h k l}^{z z}$ and equation 6 reduces to

$$
\sigma_{h k l}^{z z}=E_{h k l} \varepsilon_{h k l}^{z z}
$$

The diffraction elastic constants (DECs) for all four crystallographic grain families, measured and determined from the in-situ tensile and compressive loading in the elastic region, were $E_{111}=250 \mathrm{GPa}, E_{200}=160 \mathrm{GPa}, E_{220}=219 \mathrm{GPa}$ and $E_{311}=188$ GPa. These values were used to calculate the misfit stress along the axial direction in equations 6 and 7. The macroscopic misfit stress was derived from the macroscopic misfit strain based on the Rietveld refinement available at ENGIN-X with a Young's modulus of $210 \mathrm{GPa}$, replacing the diffraction elastic constants given in equations 6 and 7. A Poisson's ratio of 0.29 was used throughout.

\subsection{In-situ neutron diffraction measurements combined with deformation}

The POLDI instrument was used for in-situ compression tests, specimens 1 to 4 , whereas the ENGIN-X instrument was used for in-situ tension tests, specimens 6 to 9 , Table 2. Finally, specimen 5 which had been subjected to a $1000 \mathrm{~h}$ creep pre-strain, was deformed in tension at POLDI instrument. In-situ compressive incremental deformation tests were undertaken using a $30 \mathrm{kN}$ test rig at POLDI. The arrangement of a specimen in the POLDI instrument is schematically shown in Figure 2 (a), where the applied compressive stress was parallel to the diffraction vector. Specimen 5 was deformed incrementally in tension using the same test rig. Specimens 6 to 9 were incrementally deformed in tension using a $100 \mathrm{kN}$ test rig situated within the ENGIN- 
$\mathrm{X}$ instrument. The arrangement of the tensile specimen in the instrument is shown in Figure 2 (b), where the applied stress direction for the pre-strain and the in-situ deformation were co-axial. Each specimen tested at the POLDI and ENGIN-X instruments was incrementally deformed at a constant strain rate ranging from $2 \times 10^{-6}$ $\mathrm{s}^{-1}$ to $6 \times 10^{-6} \mathrm{~s}^{-1}$.

Figure 3 shows a typical applied true stress and true strain cycle used for in-situ tensile incremental deformation in the ENGIN-X instrument. In this case, specimen 8 is used for illustration. The stress level was increased step by step and unloaded at each step. An extensometer attached to the specimen provided a measure of the macroscopic mechanical strain, Figure 3 (b). At each loaded state, the specimen was held at either a constant stress (in the elastic region) or a constant strain (in the plastic region) for the period of measurement. Some stress relaxation during strain control was observed when the stress exceeded $300 \mathrm{MPa}$, Figure 3 (a). Therefore when measurements were undertaken in the plastic region and to ensure that the stress change from stress relaxation was less than $3 \mathrm{MPa}$, a pre-defined delay for starting the measurement was adopted. Three typical loaded states are shown in Figure 3 (b). At each unloaded state, the specimen was held at a stress of $5 \mathrm{MPa}$ for the period of measurement to establish the misfit strains between grains. It is these measurements that offer a monitor of the changes in the magnitude of misfit strains/stresses between grains during in-situ deformation. The measured lattice spacing at the initial state, was used as the reference condition to derive the elastic lattice strain during in-situ deformation, according to equation 5 .

\section{Results}

First experimental results are presented obtained from the initial pre-straining at high temperature. The corresponding mechanical behaviour is described together with neutron diffraction measurements of misfit stresses obtained from the pre-strained specimens. Then the macroscopic stress-strain relationships for the pre-strained specimens during in-situ deformation conducted in the ENGIN-X and POLDI instruments are described. This is followed by an examination of the elastic lattice strains measured during in-situ deformation. Finally, the evolution of the misfit stresses during room temperature in-situ deformation, revealed by the measurements at the unloaded states, is explored. 
3.1. Inelastic strains introduced by high temperature pre-straining

As described in section 2.2, specimens 2 to 5 and 7 to 9 were subjected to a tensile pre-strain at $550^{\circ} \mathrm{C}$. Figure 4 (a) shows the true stress-strain relationships for these specimens. The serrations of the stress-strain curves were caused by the use of automatic self-levelling creep rigs. This applies for specimens 3, 4, 5 and 9 . Although all the specimens were pre-strained to a value of engineering stress of 250 $\mathrm{MPa}$, there was variability in terms of the mechanical stress-strain relationship. Specimen 5 was subjected to the largest and specimen 2 to the smallest of the prestrains applied to all specimens, Figure 4 (a). This led to a $12 \mathrm{MPa}$ difference of the true stress for these pre-strained specimens, Figure 4 (a). After being subjected to a loading pre-strain, specimens 3 and 8 were allowed to creep for $160 \mathrm{~h}$; specimen 4 was crept for $720 \mathrm{~h}$; and specimens 5 and 9 were crept for $1000 \mathrm{~h}$, Figure 4 (b). Specimens 4 and 5 exhibited the same accumulated creep strain, but specimen $9 \mathrm{crept}$ at a slower rate than specimens 4 and 5. Additionally, specimens 3 and 8 crept at a slower rate than specimens 4,5 and 9 , and only a small difference of $0.3 \%$ creep strain was observed between specimens 3 and 8, Figure 4 (b).

\subsection{Misfit strains and stresses from high temperature tensile pre-straining}

Axial misfit stresses were calculated from the misfit strains for several grain families from the neutron diffraction measurements of all the specimens in their initial state (unloaded state). Stresses were determined from measured strains using equations 6 and 7. Results are shown in Figure 5 as a function of the magnitude of total inelastic strain (i.e. the sum of the plastic and creep strains) induced for each specimen. Specimens 1 to 5 were measured at POLDI, whereas specimens 6 to 9 were measured at ENGIN-X.. The axial misfit stresses for the $\{200\}$ grain family were tensile, whereas for the $\{220\}$ and $\{111\}$ grain families they were compressive. The misfit stresses for the $\{311\}$ grain family were the smallest among the four grain families considered. The magnitude of the misfit stresses increased with the increasing total inelastic strain. When there was secondary creep ( $\geq 7 \%$ total inelastic strain), the misfit stresses tended to reach a saturation value. The macroscopic misfit stresses in specimens 6 to 9, estimated by using the Rietveld refinement [26], are also shown in Figure 5. Only specimen 9 revealed a macroscopic misfit stress of about -70 
$\mathrm{MPa}$ and the macroscopic misfit stresses in other pre-strained specimens were small $(<20 \mathrm{MPa})$. Since POLDI has one neutron diffraction detector, Figure 2 (a), the calculated axial misfit stresses based on equation 7 assumed the Poisson effect for the hoop and radial directions. This might lead to the difference of the misfit stresses between specimens subjected to a similar level of pre-straining.

\subsection{Macroscopic stress-strain behaviour}

A typical macroscopic stress-strain response at room temperature together with the pre-strain response at $550{ }^{\circ} \mathrm{C}$ is shown in Figure 6 for specimen 9. The true stressstrain relationship obtained during pre-straining specimen 9 is curve OAC. In this case, specimen 9 was loaded to an engineering stress of $250 \mathrm{MPa}$ followed by a 1000 $\mathrm{h}$ creep pre-strain, curve OAC in Figure 6. Point A is the loading pre-strain and point $\mathrm{C}$ is the secondary creep pre-strain. After high temperature pre-straining, specimen 9 was cooled to room temperature and then unloaded elastically, line CO' in Figure 6. The point $\mathrm{O}^{\prime}$ is the inelastic pre-strain introduced at $550{ }^{\circ} \mathrm{C}$. Finally, specimen 9 was subjected to an in-situ tensile deformation at room temperature combined with neutron diffraction measurements. Collated tensile and compressive room temperature stress-strain curves are shown in Figure 7. Note that all the compressive curves have been reversed to permit comparison with the tensile stress-strain curves. When results from specimens 1 and 6 (i.e. in the non-pre-strained condition) are compared there is slightly more hardening in compression than in tension, Figure 7. However, for all pre-strained specimens the compressive curves illustrate transient softening. This is seen in Figure 7 for specimens 2, 3 and 4. Figure 7 reveals there is no evidence of permanent softening as discussed in the introduction, i.e. $\sigma_{p s}$ was zero in Figure 1. For the pre-strained specimens, the level of the true stress obtained during reversed loading in compression increased with the increasing inelastic strain to a similar level to that obtained during continued loading in tension. In the case of specimens 3 and 4 , a level of $1.7 \%$ inelastic strain was required to reach this critical point, Figure 7.

Figure 8 shows the macroscopic stress-strain relationships for specimens 4 and 9 in more detail. The values of the stresses $\left|\sigma_{r 0}\right|$ and $\sigma_{f 0}$, as well as the magnitude of the transient softening stress, $\sigma_{t s}$, are highlighted in Figure 8. Inelastic material flow occurred at a lower applied stress for specimen 4 in compression compared with 
specimen 9 when loaded in tension. Based on the known resolution of the extensometer, a strain offset of $\varepsilon_{o f f}=10^{-4} \mathrm{~mm} / \mathrm{mm}$ was employed to determine these stresses. $\sigma_{f 0}$ and $\left|\sigma_{r 0}\right|$ were found to be $355 \mathrm{MPa}$ and $220 \mathrm{MPa}$ for specimens 9 and 4, respectively. Thus the magnitude of the transient softening, $\sigma_{t s}$, (equal to the difference between $\sigma_{f 0}$ and $\left.\left|\sigma_{r 0}\right|\right)$, was $135 \mathrm{MPa}$. These results were used to determine the isotropic and kinematic stresses, $\sigma_{\kappa}$ and $\sigma_{\alpha}$, based on equations $4 \mathrm{a}$ and $4 \mathrm{~b}$. The initial yield strength, $\sigma_{0}=172 \mathrm{MPa}$, was determined from the average value of the elastic limit obtained from the non-pre-strained specimens 1 and 6.

Similar analyses were carried out for all specimens shown in Figure 7 to determine the isotropic and kinematic hardening stresses. The resulting values of $\sigma_{\kappa}$ and $\sigma_{\alpha}$ are shown in Figure 9. For the non-pre-strained condition, there was a small difference of $2 \mathrm{MPa}$ between specimens $1\left(\sigma_{r 0}\right)$ and $6\left(\sigma_{f 0}\right)$. This led to a non-zero stress for isotropic hardening, $\sigma_{\kappa}$, and kinematic hardening, $\sigma_{\alpha}$, for the reference (non-prestrained) condition, Figure 9. High temperature pre-straining created an increase in both the isotropic and kinematic hardening stresses. Subsequent primary creep prestrain resulted in an increased isotropic hardening stress, $\sigma_{\kappa}$, but a decrease in the kinematic hardening stress $\sigma_{\alpha}$. However, further pre-straining arising from the secondary creep did not change the values of either stresses, $\sigma_{\kappa}$ or $\sigma_{\alpha}$.

\subsection{Elastic lattice strains during in-situ deformation}

In-situ neutron diffraction measurements were undertaken at incrementally increased loads, as described in section 2.4 and shown in Figure 3 (b). Specimen 1 was deformed in compression and specimen 6 in tension. The measured axial elastic lattice strains as a function of the applied stresses for specimens 1 (compression) and 6 (tension) are shown in Figures 10 (a) and (b). For specimen 1 loaded in compression the results are presented as the absolute elastic lattice strain as a function of the absolute applied stress. For the $\{220\},\{311\}$ and $\{111\}$ grain families, there was no noticeable difference between the measured elastic lattice strains for specimens 1 and 6, Figures 10 (a) and (b). However, there was an axial strain difference of $\Delta \varepsilon_{200}^{z z}=420 \times 10^{-6}$ for the $\{200\}$ grain family, Figure 10 (a).

In contrast to specimens 1 and 6 , specimens 4 and 9 were subjected to secondary creep pre-strains, and then specimen 4 was compressed in-situ whereas specimen 9 
was loaded in tension in-situ, Table 2. The lattice strains from these tests are shown in Figures 10 (c) and (d). Figure 10 (c) shows that the $\{200\}$ and $\{220\}$ grain families for specimen 4 (compressively deformed) had larger deviations from linearity when compared with specimen 9 (deformed in tension). In the case of the specimens 4 and 9 , the strain difference for the $\{200\}$ grain family was $\Delta \varepsilon_{200}^{z z}=1760 \times 10^{-6}$ Figure 10 (c). This value is greater than the strain difference of $\Delta \varepsilon_{200}^{z z}=420 \times 10^{-6}$ between specimens 1 and 6, as shown in Figure 10 (a). Additionally, a strain difference for the $\{220\}$ grain family of $\Delta \varepsilon_{220}^{z z}=500 \times 10^{-6}$ between specimens 4 and 9 is shown in Figure 10 (c). The large deviations from linearity for both the $\{200\}$ and $\{220\}$ grain families in the secondary creep pre-strained specimen 4 infers that micro-yielding occurred during in-situ compressive loading. This has been discussed in detail by Chen et al. [20] and Clausen et al. [28]. A small strain difference between specimens 4 and 9 was also observed for the $\{311\}$ grain family, Figure $10(d)$. Specimens 4 and 9 represent one pair of pre-strained specimens; and in terms of the measured elastic lattice strains similar phenomena were observed in the other pairs of pre-strained specimens. These observations reveal that the misfit strains/stresses created at $550{ }^{\circ} \mathrm{C}$ through plastic and creep pre-straining were changed during in-situ compressive deformation.

\subsection{Evolution of misfit stresses during in-situ deformation}

The neutron diffraction measurements undertaken at a series of unloaded states, as illustrated by specimen 8 in Figure 3 (b), provided a measure of the changes in the initial misfit stresses (created by high temperature pre-straining) during subsequent room temperature deformation. Since different magnitudes of the misfit stresses were created by pre-straining the specimens to different stages of high temperature deformation, as shown in Figure 5, the evolution of misfit stresses during in-situ deformation are presented in two stages. First, the misfit stresses are evaluated by comparing the lattice spacings in the unloaded states with those prior to undertaking in-situ loading are presented in Figure 11. Second, these measured misfit stresses are added to the pre-straining induced misfit stresses, as shown in Figure 12. Results from specimens 4 and 9 (secondary creep pre-strained) are used as an illustration. The horizontal axes in both Figures 11 and 12 are the measured macroscopic inelastic 
strains; thus negative values on the horizontal axis in Figure 11 (b) correspond to insitu compression. Figure 11 (a) shows the misfit stresses of four grain families for specimen 9, (secondary creep pre-strained and then in-situ tensile loaded). The largest change in misfit stress was $-71 \mathrm{MPa}$ for the $\{200\}$ grain family; although generally there were insignificant changes in misfit stresses resulted from the in-situ tensile deformation for the other grain families. In contrast, Figure 11 (b) shows the misfit stresses of four grain families for specimen 4 (pre-strained via secondary creep and then in-situ compression). In this case, a change in the compressive misfit stress of $-241 \mathrm{MPa}$ occurred in the $\{200\}$ grain family, whereas a tensile misfit stress of 129 $\mathrm{MPa}$ occurred in the $\{220\}$ grain family. By comparison, a smaller change in the tensile misfit stress of $55 \mathrm{MPa}$ was associated with the $\{111\}$ grain family, Figure 11 (b). The change in misfit stress for the $\{311\}$ grain family was found to be less than $20 \mathrm{MPa}$.

When taking into account the pre-existing misfit stresses for the four grain families of the pre-strained specimens, as shown in Figure 5, room temperature in-situ deformation modified the state of misfit stresses. The evolution of the pre-strain induced misfit stresses as a function of the total inelastic strain is shown in Figure 12. The total inelastic strain is a sum of the high temperature pre-strain and room temperature in-situ deformation introduced inelastic strain. Point $\mathrm{O}^{\prime}$ in both Figures 12 (a) and (b) indicates the amount of high temperature pre-strain, as summarised in Table 2. As a result, the origin of data for specimen 9 is at $6.9 \%$ inelastic strain for the horizontal axis in Figure 12 (a) and an increasing inelastic strain in this figure indicates room temperature tensile deformation. Specimen 4 was deformed in-situ in compression and the inelastic strain decreases from the original value of $6.8 \%$ inelastic strain, Figure 12 (b). The misfit stress in the $\{200\}$ grain family reduced from $98 \mathrm{MPa}$ at $6.9 \%$ strain to $27 \mathrm{MPa}$ at $8.95 \%$, leading to a total stress change of 71 $\mathrm{MPa}$, Figure 12 (a). Figure 12 (b) shows the evolution of the misfit stresses for all four grain families in specimen 4. In this case, the misfit stress in the $\{200\}$ grain family changed from $80 \mathrm{MPa}$ at $6.8 \%$ strain to $-161 \mathrm{MPa}$ at $5.35 \%$ strain, leading to a total stress change of $241 \mathrm{MPa}$, Figure 12 (b). For the $\{220\}$ grain family, the misfit stress changed from -94 MPa to $35 \mathrm{MPa}$, leading to a total stress change of $129 \mathrm{MPa}$, Figure 12 (b).

Also observed in Figure 12 (b) is the rate of change of the misfit stresses for specimen 4 decreases with increasing room temperature inelastic strain. For instance, 
the changes in stress from the measurements at strains of $\sim 6.0 \%$ to $\sim 5.4 \%$ were insignificant compared with the changes in initial stress from the measurements at strains of $6.8 \%$ to $\sim 6.4 \%$, Figure 12 (b). This indicates that the changes of the misfit stresses tended to vanish at a certain level of inelastic strain. This is consistent with the macroscopic stress-strain behaviour observed in Figure 8, where the difference between the continued tensile deformation and reversed compressive deformation tends to be reduced with the increasing strain. Thus it is likely that the observed changes from the transient softening to the permanent softening in the pre-strained specimens are associated with the changes in the misfit stresses.

Similar analyses were adopted to determine the changes in the magnitude of misfit stresses during in-situ deformation for all specimens given in Table 2. Results are summarised in Table 3. Both specimens 1 (compressively deformed) and 6 (deformed in tension) were not subjected to a high temperature pre-straining and the magnitude of the misfit stress changes in all four grain families for these two specimens were similar, Table 3. Specimens 5 and 9 were subjected to a secondary creep pre-straining. These two specimens were then subject to in-situ tensile deformation at the POLDI and ENGIN-X. The changes in the magnitude of the misfit stresses for these two specimens were insignificant. However, when comparing the changes in the misfit stresses in specimens 2, 3 and 4, with the corresponding specimens 7,8 and 9 (or 5), the magnitude of the misfit stress changes were greater in pre-strained specimens 2,3 and 4 ; in particular the $\{200\}$ and $\{220\}$ grain families.

\section{Application of a Multi-scale Self-consistent Model}

To provide further insight into the experimental results described above, we analyse experiments in which a specimen is subjected to plastic pre-straining at elevated temperature, followed by tensile or compressive loading at room temperature, using a multi-scale self-consistent model. This model provides detailed information about the evolution of stress in the individual grains of the polycrystal. The model is an extension of a previous model developed by the authors [20, 29], and incorporates the effect of solute strengthening on the plastic response of the material. We limit our consideration to elastic and plastic deformation and do not examine the effects of creep pre-straining. The effects of recovery of the dislocation structure and creep on the evolution of the internal stress is the subject of ongoing research. 


\subsection{Summary of model}

Here we provide a brief outline of the model. Further details can be found elsewhere [30]. The model consists of three sub-models: (i) continuum, (ii) crystal plasticity and (iii) dislocation link length models where the last of these is based on a model originally proposed by Lagneborg and Forsen [17]. The self-consistent continuum scheme establishes the relationship between the response of each individual grain and the bulk response of the polycrystalline aggregate [31]. During macroscopic plastic deformation, misfit stresses between grains develop due to the accumulation of incompatible plastic mismatch strains between grains. Plastic strain increments within each grain are calculated using a crystal plasticity framework [32, 33]. This is achieved by adding all the shear strain increments on all the active slip systems within the grain, which are determined using a rate-dependent power-law such that dislocation slip occurs on this slip system only when the resolved shear stress approaches the critical resolved shear strength ${ }^{2}$ (CRSS) on the same slip system. The dislocation link length model describes a two-dimensional distribution of forest dislocations on the slip planes of each individual grain. The distribution of dislocation link lengths is related to the distribution of pinning points. The CRSS on a slip plane in the model is defined as the shear stress required for a dislocation to penetrate the whole slip plane and is inversely proportional to the mean spacing of the pinning points on the slip plane. The initial CRSS is assumed to be identical for all the slip systems of each individual grain. Self and latent hardening of each slip plane is associated with the evolution of the distribution of pinning points.

The strengthening effect of solute elements on the resistance to dislocation slip is also incorporated in this model. Similar to the dislocation link length model, resistance on a slip plane is considered to be inversely proportional to the mean spacing of all the solute atoms on the plane, which can be calculated from the given solute concentration in the material. Variation of the distribution of solute atoms on different slip planes is not considered, thus solute strengthening is simplified as isotropic on all the slip systems. The overall CRSS on each slip system is determined by a combination of both solute and dislocation strengthening, following a linear

\footnotetext{
${ }^{2}$ In the recent full review article by Chen et al. [34], it has been demonstrated that it is important to separate the resistance term from the stress term when developing the constitutive deformation model. Thus here we use the term critical shear strength, rather than critical shear stress.
} 
superposition rule [35].

All contributions to the CRSS in the model are proportional to the shear modulus (through its effect on the line tension), which is a function of temperature. Thus when the temperature is changed the CRSS is rescaled using the temperature dependence of the modulus $[17,18]$. Note that the misfit strain for each individual grain developed during high temperature pre-straining remains the same, but the misfit stress scales with the temperature-dependent modulus. The model provides information about the evolution of dislocation link length, the kinematics of the slip process, the misfit stress between grains and the bulk response of the material. The latter two will be presented for a comparison with the experimental data.

\subsection{Comparison of experimental data and model predictions}

The experimental results obtained from specimens 2 (compressive) and 7 (tensile) are used for comparison with the model predictions. Parameters ${ }^{3}$ within the model were selected to provide the correct macroscopic stress-strain curve for the tensile pre-straining $(1.9 \%)$ at $550{ }^{\circ} \mathrm{C}$ for both specimens 2 and 7 , as shown in Figure 13 (a). The resulting model was then employed to predict the room temperature response in tension and compression. The tensile pre-straining at $550{ }^{\circ} \mathrm{C}$ introduced different misfit elastic strains into different grains. The model predictions of the macroscopic response during subsequent re-loading at room temperature in tension for specimen 7 and in compression for specimen 2 are shown in Figure 13 (b) together with the insitu experimental data. The general trends in the transient softening behaviour observed experimentally in compression, compared with that in tension, is predicted by the model. We have also determined the isotropic and kinematic stresses ( $\sigma_{\kappa}$ and $\left.\sigma_{\alpha}\right)$ from the model and these are in good agreement with the experimentally determined stresses as shown in Figure 9.

Figures 14 (a) and (b) compare the model predictions with the experimentally measured elastic lattice strains for specimens 2 and 7. Discontinuous changes in the slopes of the grain families illustrated by arrows 1 to 6 in Figures 14 (a) and (b) are associated with micro-yielding in the polycrystalline material. During compressive loading, the gradual increase in the slopes in both the $\{200\}$ and $\{220\}$ grain families

\footnotetext{
${ }^{3}$ A total of three parameters are related to the initial distribution of pinning points and the rates of selfand latent hardening. All other parameters are determined from geometric or physical requirements.
} 
suggests that micro-yielding occurred somewhere in the surrounding homogeneous material, resulting in a transfer of stress from these regions to the grain family under consideration. The almost zero increase in the elastic lattice strain at arrow 5 in Figure 14 (b) for the $\{220\}$ grain family and at arrow 3 in Figure 14 (a) for the $\{200\}$ grain

family of specimen 2 indicates the presence of micro-yielding in each corresponding grain family, with the stress being transferred to other grains within the body which are yet to yield. The gradual increase in the slopes for both the $\{200\}$ and $\{220\}$ grain families suggests that micro-yielding occurred somewhere in the surrounding homogeneous material, resulting in a transfer of stress from these regions to the grain family under consideration. While the model captures the general trends observed experimentally, there are noticeable differences between the model predictions and the measurements. These differences are discussed in section 5.2.

\section{Discussion}

\subsection{Bauschinger effect}

Following the seminal consideration of the effects of misfit stresses by Orowan [36], several phenomenological theories have been developed to describe the transient stress-strain response of polycrystalline materials under reversed loading [37, 38]. Although complex and refined models based on the concept of misfit stresses have also been developed [39-41], to date none of the studies has provided either a direct measure of the magnitude of the misfit stresses or addressed how stresses evolve during the reversed loading. A detailed theoretical explanation for the presence of transient softening under reversed loading was proposed by Orowan [42], but no experimental evidence was available to support the hypothesis. The present work, based on the in-situ deformation combined with the neutron diffraction measurements, provides a measure of misfit stress for specific grain families under reversed loading.

For all the specimens pre-strained at $550{ }^{\circ} \mathrm{C}$ the compressive stress-strain curves contain evidence of transient softening, as illustrated by the behaviour of specimens 2 , 3 and 4 in Figure 7. By comparison, the tensile stress-strain curves obtained from specimens 7, 8 and 9 follow a common stress-strain relationship. Also none of the pre-strained specimens exhibited permanent softening during compression. The absence of the permanent softening is consistent with the previously observed 
phenomena associated with the single phase polycrystalline materials. In an early study by Wilson [43], the presence of permanent softening during reversed straining was found to be associated with a distribution of second phase precipitates that provided a strong barrier to dislocation movement. In addition a transient softening stress, $\sigma_{t s}$, was observed when undertaking mechanical tests to evaluate the Bauschinger effect on several single phase, cubic symmetry polycrystalline materials, including $\mathrm{Al}$ and $\mathrm{Cu}$ alloys [43]. X-ray diffraction measurements were undertaken to provide the magnitude of misfit stresses for one or two grain families [43]. However X-ray measurements provide near surface stresses so that stress relaxation within the surface arising from specimen preparation could not be avoided. As a consequence, Wilson [43] did not link the transient softening behaviour of the single phase polycrystalline material with the presence of the misfit stresses for different grain families.

The present results reveal that misfit stresses created during high temperature prestraining of Type $316 \mathrm{H}$ austenitic stainless steel are dependent on the crystallographic orientations of the grains, Figure 5. The $\{200\}$ grain family had an increasing tensile misfit stress as the level of the pre-strain was increased, whereas the $\{220\}$ grain family had an increasing compressive misfit stress. The magnitude of misfit stresses did not change significantly when the specimen was subsequently subject to in-situ room temperature tensile deformation, Figure 12 (a). This is supported by the results from in-situ tensile deformation of specimen 9, where the measurements were undertaken during loading, Figures 10 (c) and (d). However, there was a significant change of the misfit stresses created by high temperature pre-strain when subsequently subject to an in-situ compressive deformation, Figure 12 (b). In addition, measurements undertaken during loading show that elastic lattice strains deviated significantly from linearity, in particular for the $\{200\}$ and $\{220\}$ grain families, Figure 10 (c). Thus the presence of the transient softening in the macroscopic stressstrain relationship of a single phase polycrystalline material, for example as shown in Figure 7, is associated with the misfit strains/stresses between grains. 


\subsection{Predictions from the model}

The self-consistent model has assumed a zero misfit stress condition for each individual grain within the polycrystal before the pre-straining. In practice, provided the pre-strain is large enough, the misfit stresses at the end of pre-straining are not very sensitive to the initial distribution of stress for the grains. A specific misfit stress field is obtained from the high temperature pre-straining that allows all of the grains to yield at the same time during the subsequent room temperature tensile loading. This accounts for the sharp change in slope of the macroscopic stress-strain curve at yield in Figure 13 (a) for the model. When the applied tensile stress is small, both the model prediction and the experimental data show that the lattice strain responses of both the $\{200\}$ and $\{220\}$ grain families are elastic, Figures 14 (a) and (b). Beyond yield, the model still predicts a slope similar to the elastic response for both grain families. This indicates that grains deform compatibly plastically. However, experimentally there is a more distinct increase in the slope for the $\{200\}$ grain family of Figure 14 (a), before it decreases again to become parallel to the elastic response line. The trend for the $\{220\}$ grain family in Figure 14 (b) is less clear, but there is evidently a sharper decrease in slope in the experimental result. The discrepancy between the model and in-situ experiment could result from a number of related physical processes: (i) the misfit stresses between grains could have relaxed either during or after high temperature pre-straining, (ii) creep could have contributed to the inelastic deformation during the high temperature pre-straining, or (iii) the mechanism of plastic flow at elevated temperature is different to that at room temperature. In either case, the misfit stresses between grains generated by the pre-straining is different from that required to ensure compatibility of plastic deformation of the grains during loading at room temperature. Therefore the stresses redistribute during the initial stages of plastic deformation until a suitable misfit stress state that gives rise to compatible plastic straining is established. As a result, the experimentally obtained RT tensile re-loading curve, Figure 13 (a), shows a more gradual yielding process (i.e. there is a less sharp definition of yield) than predicted by the model.

In contrast to the tensile loading case described above, the misfit stress state established during high temperature pre-straining is significantly different to that which is required to give compatibility of plastic straining in compression. Therefore plastic flow occurs much earlier in some grains than in others and the change in slope 
of the stress-strain curve is less sharp, while the misfit stress state redistributes as the number of grains that deform plastically gradually increases. Compared with the model prediction, the experimental data for the $\{200\}$ grain family shown in Figure 14 (a) suggests earlier yielding in the surrounding matrix (before arrow 1, where the slope increases) and earlier yielding in the $\{200\}$ grain family (before arrow 3 where there is a sharp decrease of slope). This is because the self-consistent model does not take into account the effect of the orientation of neighbouring grains; it assumes that all neighbours take the average response of the polycrystal. However, in practice, the detailed response of a given grain will depend on the crystallographic orientation of its neighbours. Thus members of a given grain family may not always experience the same lattice response, i.e. the actual yielding characteristics for each grain family should be smooth rather than the sharp feature predicted by the model shown in Figure 14 (a). A similar effect can be observed in the $\{220\}$ grain family shown in Figure 14 (b). When the applied compressive stress is high, a suitable misfit stress state is expected to be established that promotes compatible plastic deformation of the grains. The slopes of Figure 14 would then change back towards the initial elastic slope. This is clearly evident for the $\{200\}$ grain family of Figure 14 (a), but this condition has not yet been achieved for the $\{220\}$ grain family of Figure 14 (b). This suggests that the full steady state misfit stress state has not been achieved at this macroscopic stress level. This is consistent with the observation that the compressive macroscopic stress-strain curve appears to be asymptoting towards, but has not yet met, that for tensile loading, see Figure 13 (b). We would also expect to observe this type of asymptotic response, independent of how the initial internal stress state is established (whether by prior plastic or creep deformation). It is more clearly demonstrated in Figure 8, which compares the tensile and compressive responses following a period of tensile creep at elevated temperature.

\section{Conclusions}

It may be concluded:

(1) In-situ neutron diffraction measurements provide important information about the evolution of misfit stresses associated with different $\{h k l\}$ grain families in pre-strained polycrystalline Type $316 \mathrm{H}$ austenitic stainless steel when strained under reversed loading. 
(2) The presences of the transient softening and zero permanent softening in high temperature pre-strained Type $316 \mathrm{H}$ austenitic stainless steels have been observed.

(3) The changes in the misfit stresses for both the $\{220\}$ and $\{200\}$ grain families are consistent with the change in the transient softening stress towards a zero permanent softening stress.

(4) A multi-scale self-consistent model predicts similar macroscopic stress-strain relationships as well as the grain family responses to the experimental observations.

(5) The origin of the kinematic hardening for Type $316 \mathrm{H}$ austenitic stainless steel arises from the misfit stress between grains.

\section{Acknowledgements}

Bo Chen and Jia Nan Hu are grateful to EDF Energy plc. for the financial support. David Smith is supported by the Royal Academy of Engineering, EDF Energy and Rolls Royce plc. Peter Flewitt acknowledges Wolfson College, Oxford University, for facilitating this collaboration. 


\section{References}

[1] Kocks UF, Mecking H, Prog. Mater. Sci. 2003;48:171.

[2] Blum W, Mater. Sci. Eng. A 2001;319:8.

[3] Cadek J, Mater. Sci. Eng. 1987;94:79.

[4] Vincze G, Rauch EF, Gracio JJ, Barlat F, Lopes AB, Acta Mater 2005;53:1005.

[5] Bauschinger J, Mitt. Mech. Tech. Lab. Munchen 1886;13:1.

[6] Buckley SN, Entwistle KM, Acta Metall. 1956;4:352.

[7] Bate PS, Wilson DV, Acta Metall. 1986;34:1097.

[8] Wilson DV, Bate PS, Acta Metall. 1986;34:1107.

[9] Ikegami K, Niitsu Y, Int. J. Plas. 1985;1:331.

[10] Hasegawa T, Yakou T, Karashima S, Mater. Sci. Eng. 1975;20:267.

[11] Christodoulou N, Woo OT, MacEwen SR, Acta Metall. 1986;34:1553.

[12] Rauch EF, Gracio JJ, Barlat F, Acta Mater 2007;55:2939.

[13] Horstemeyer MF, Bammann DJ, Int. J. Plas. 2010;26:1310.

[14] Freed AD, Chaboche JL, Walker KP, Acta Mech. 1991;90:155.

[15] Schmidt CG, Miller AK, Res. Mech. 1981;3:175.

[16] Schmidt CG, Miller AK, Acta Metall. 1982;30:615.

[17] Lagneborg R, Forsen BH, Acta Metall. 1973;21:781.

[18] Frost HJ, Ashby MF, Deformation-mechanism Maps, Pergamon, Exeter, 1982.

[19] Miller MP, Harley EJ, Bammann DJ, Int. J. Plas. 1999;15:93.

[20] Chen B, Hu JN, Flewitt PEJ, Smith DJ, Cocks ACF, Zhang SY, Acta Mater. 2014;67:207.

[21] Chen B, Flewitt PEJ, Smith DJ, Jones CP, Ultramicroscopy 2011;111:309.

[22] Chen B, Flewitt PEJ, Smith DJ, Mater. Sci. Eng. A 2010;527:7387.

[23] Santisteban JR, Daymond MR, James JA, Edwards L, J. Appl. Cryst. 2006;39:812.

[24] Stuhr U, Nucl. Instrum. Methods Phys. Res. 2005;545:319.

[25] Stuhr U, Spitzer H, Egger J, Hofer A, Rasmussen P, Graf D, Bollhalder A, Schild M, Bauer G, Wagner W, Nucl. Instrum. Methods Phys. Res. 2005;545:330.

[26] Daymond MR, Bourke MAM, Von Dreele RB, Clausen B, Lorentzen T, J. Appl. Phys. $1997 ; 82: 1554$.

[27] Weisser MA, Evans AD, Van Petegem S, Holdsworth SR, Van Swygenhoven H, Acta Mater 2011;59:4448.

[28] Clausen B, Lorentzen T, Leffers T, Acta Mater 1998;46:3087.

[29] Hu JN, Chen B, Smith DJ, Flewitt PEJ, Cocks ACF, Self-consistent modeling and the evaluation of lattice deformation in a polycrystalline austenitic stainless steel, In: Joint 3rd UK-China Steel Research Forum \& 15th CMA-UK Conf. Mater. Sci. Eng., ISIS, UK, Materials Today: Proceedings, 2014.

[30] Hu JN, A Theoretical Study of Creep Deformation Mechanisms of Type 316H Stainless Steel at Elevated Temperatures, Department of Engineering Science (PhD), University of Oxford, Oxford, 2015

[31] Kroner E, Acta Metall. 1961;9:155.

[32] Asaro RJ, Needleman A, Acta Metall. 1985;33:923.

[33] Hill R, J. Mech. Phys. Solids 1966;14:95.

[34] Chen B, Flewitt PEJ, Cocks ACF, Smith DJ, Int. Mater. Rev. 2014 (In Press).

[35] Dong Y, Nogaret T, Curtin WA, Metall. Mater. Trans. A 2010;41:1954.

[36] Orowan E, Discussion, In: Symp. on Internal Stresses, London, Inst. Metals, 1947.

[37] Prager W, J. Appl. Phys. 1949;20:235.

[38] Mroz Z, J. Mech. Phys. Solids 1967;15:163.

[39] Chaboche JL, Rousselier G, Trans. ASME, J. Press. Vessel Technol. 1983;105:153.

[40] Mroz Z, Trans. ASME J. Eng. Mater. Technol. 1983;105:113.

[41] Hu ZQ, Rauch EF, Teodosiu C, Int. J. Plas. 1992;8:839.

[42] Orowan E, In: Symp. Internal Stresses and Fatigue in Metals, Detroit and Warren, Michigan, Elsevier, 1958.

[43] Wilson DV, Acta Metall. 1965;13:807. 


\section{Figure Captions}

Figure 1 Schematic diagram of a stress-strain history applied to a specimen, showing prior tensile creep deformation (curve OABC) and continued (tensile) and reversed (compressive) straining of the material at room temperature.

Figure 2 Arrangement of the specimens in the neutron diffraction instruments used to measure the misfit strains along the bisector between the incident and the diffracted beams: (a) in-situ compressive deformation at POLDI; (b) in-situ tensile deformation at ENGIN-X.

Figure 3 Stress and strain cycles applied to specimen 8 (160 h creep pre-strain) when undertaking incremental tensile deformation at room temperature combined with neutron diffraction measurement at ENGIN-X: (a) applied true stress versus elapsed time; (b) macroscopic true strain versus elapsed time.

Figure 4 High temperature $\left(550^{\circ} \mathrm{C}\right)$ tensile pre-straining applied to specimens 2 to 5 and 7 to 9: (a) tensile stress-strain behaviour; (b) creep strains during the subsequent creep for $160 \mathrm{~h}$ (specimens 3 and 8), $720 \mathrm{~h}$ (specimen 4) and $1000 \mathrm{~h}$ (specimens 5 and 9). Specimens IDs have been given in Table 2.

Figure 5 Axial misfit stresses together with the macroscopic misfit stresses due to high temperature (HT) pre-strain of specimens 1 to 5 measured at POLDI and specimens 6 to 9 measured at ENGIN-X. Numbers correspond to the specimen IDs given in Table 2.

Figure 6 High temperature $\left(550{ }^{\circ} \mathrm{C}\right)$ stress-strain behaviour of specimen 9 subjected to a $1000 \mathrm{~h}$ creep pre-strain, followed by in-situ room temperature tensile loading at the ENGIN-X instrument. HT: high temperature; RT: room temperature.

Figure 7 Stress-strain behaviour for four pairs of specimens, where each pair consists of an in-situ tensile loaded specimen and an in-situ compressively loaded specimen. Numbers correspond to specimen IDs given in Table 2. HT: high temperature; RT: room temperature. Note that compressive data are in absolute units to permit comparison with the tensile stress-strain curves.

Figure 8 The Bauschinger effect observed as a result of high temperature prestraining (secondary creep and unloaded). Results are shown for stress-strain 
behaviour in specimen 4 subjected to a compressive deformation and specimen 9 subjected to a tensile deformation. The inserted figure is a magnified view of the transient softening and illustrates the determination of $\sigma_{t s}$.

Figure 9 Experimentally determined isotropic and kinematic hardening stresses, $\sigma_{\kappa}$, and $\sigma_{\alpha}$, based on the macroscopic stress-strain behavior illustrated in Figure 7. Also shown in this figure are values from the model derived from loading pre-strained specimens. Measurement errors were derived from the determination of yield strength using the strain offset of $10^{-4} \mathrm{~mm} / \mathrm{mm}$.

Figure 10 Axial elastic lattice strains during in-situ loading of specimens 6 and 9 in tension and specimens 1 and 4 in compression: (a) the $\{220\}$ and $\{200\}$ grain families for non-pre-strained specimens 1 and 6 ; (b) the $\{311\}$ and $\{111\}$ grain families for non-pre-strained specimens 1 and 6; (c) the $\{220\}$ and $\{200\}$ grain families for secondary creep pre-strained specimens 4 and 9; (d) the $\{311\}$ and $\{111\}$ grain families for secondary creep pre-strained specimens 4 and 9.

Figure 11 Axial misfit stresses created by in-situ deformation of specimens 4 and 9 which received a secondary creep pre-strain: (a) specimen 9 was deformed in tension and (b) specimen 4 was deformed in compression. Note that the horizontal axis refers to the room temperature in-situ deformation in both (a) and (b) and the scale ranges are different.

Figure 12 Evolution of the axial misfit stresses created by pre-strain during the in-situ deformation of specimens 4 and 9: (a) specimen 9 was deformed in tension and (b) specimen 4 was deformed in compression. Note that different scale ranges are used for the total inelastic strain in both (a) and (b).

Figure 13 Comparison of experimental data and model prediction for the macroscopic stress-strain behaviour: (a) high temperature $\left(550{ }^{\circ} \mathrm{C}\right)$ tensile loading prestrain and the subsequent room temperature tensile re-loading subjected by specimen 7; (b) room temperature stress-strain relationship in specimen 2 subjected to a compressive loading and specimen 7 subjected to a tensile loading. HT: high temperature; RT: room temperature. Specimens IDs are given in Table 2.

Figure 14 Comparison of experimental data and model prediction for the axial elastic lattice strains during room temperature in-situ loadings of high temperature 
pre-strained specimens: (a) the $\{200\}$ grain families of specimens 2 (compression) and 7 (tension); (b) the $\{220\}$ grain families of specimens 2 (compressive) and 7 (tensile). The arrows depict the predicted discontinuities in the slopes of the grain families responding to external loading. Specimens IDs are given in Table 2. 


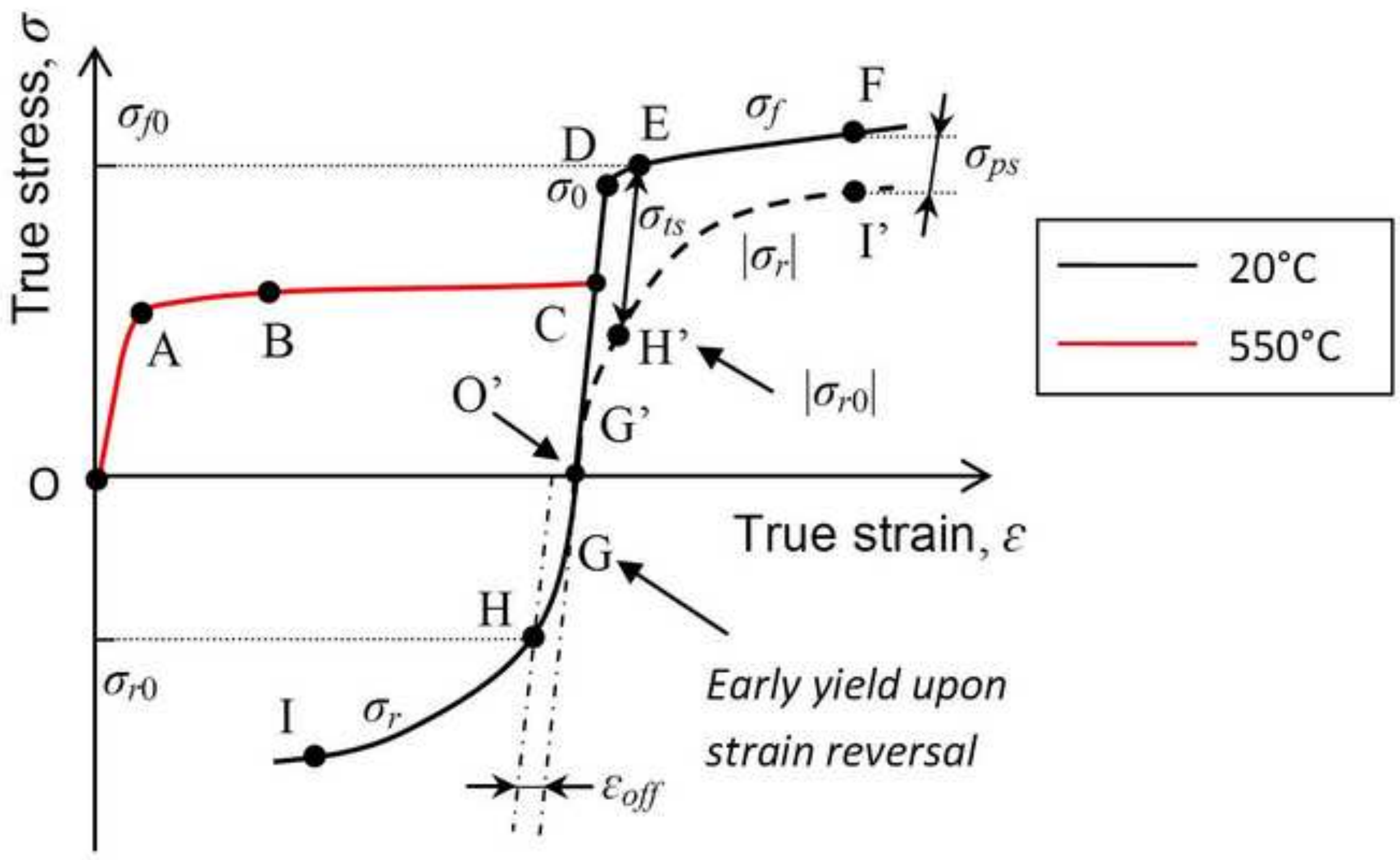


Incident continuous spallation neutron

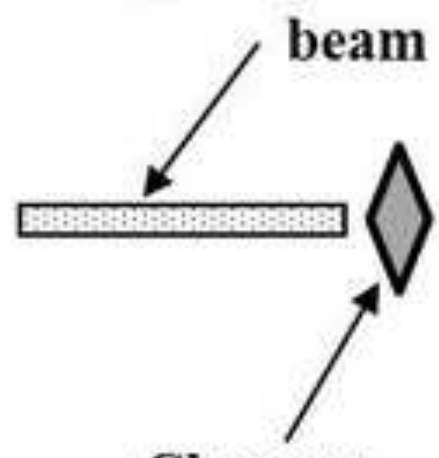

Chopper

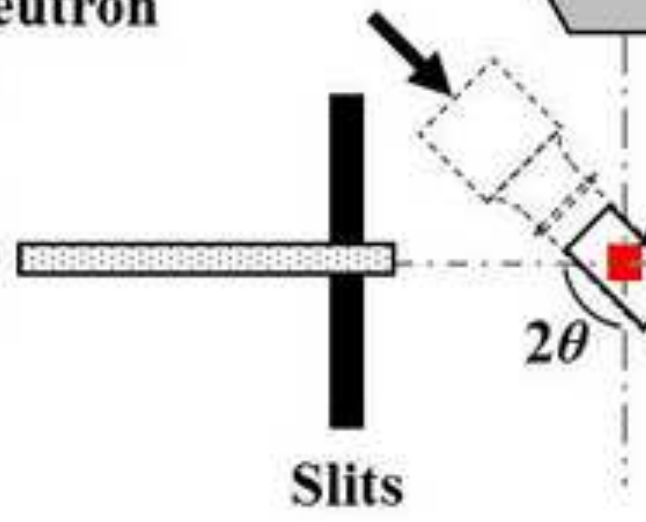

Slits

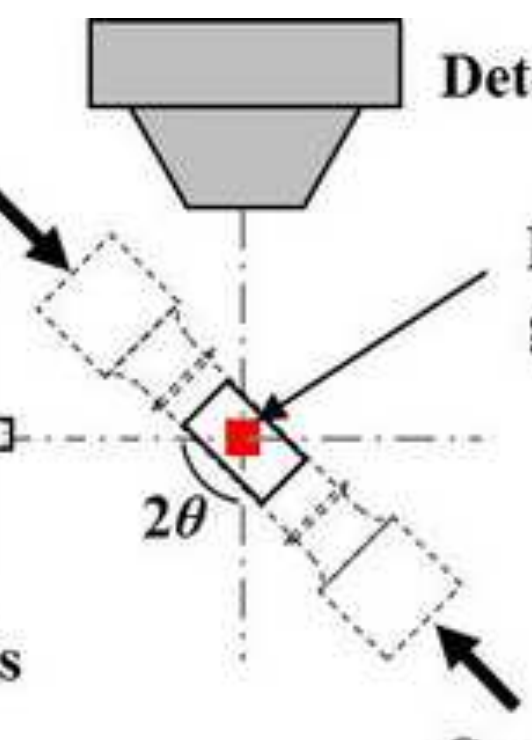

Compressive stress axis

(a)

Incident pulsed neutron beam

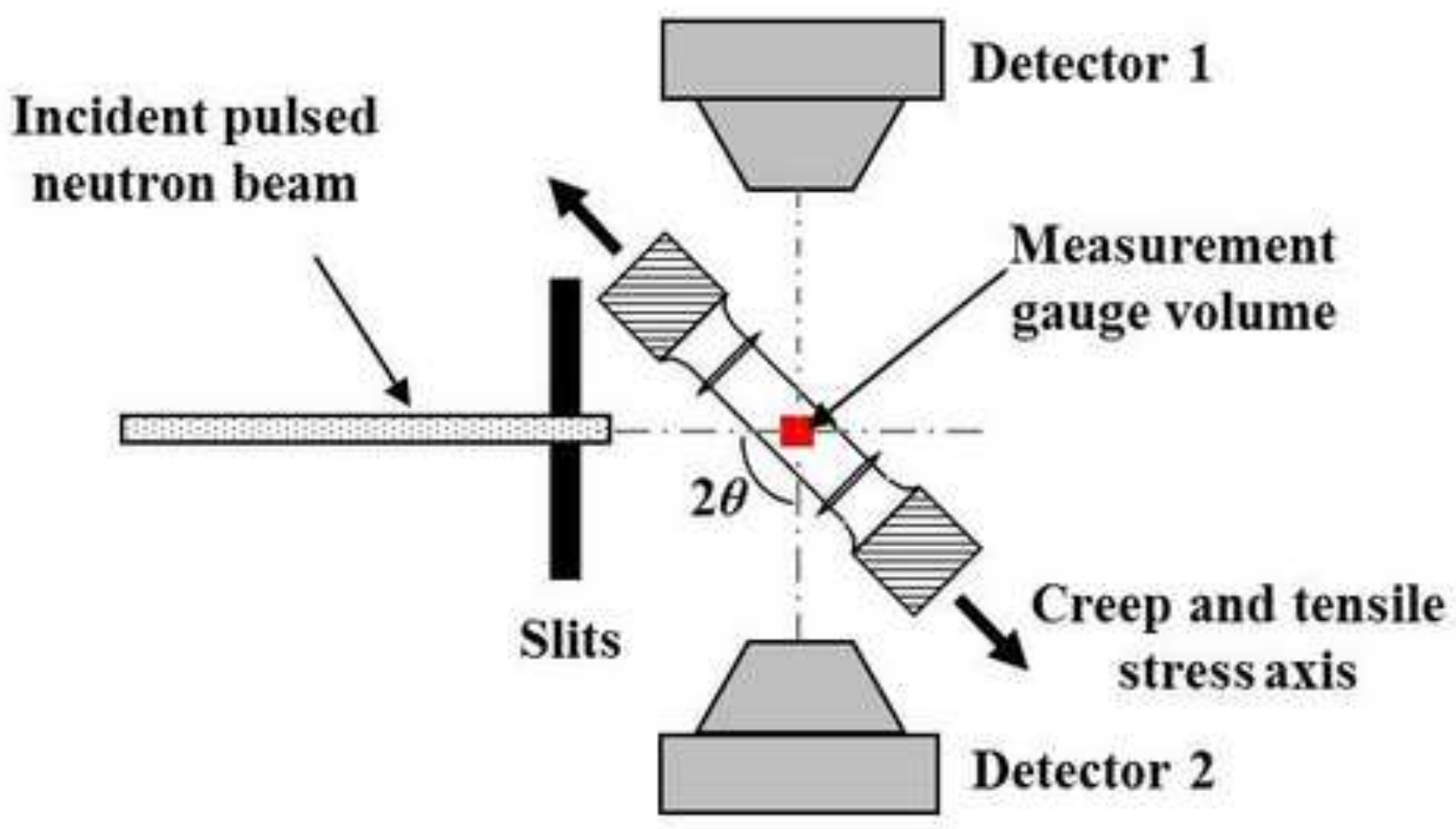

(b)

Measurement gauge volume 


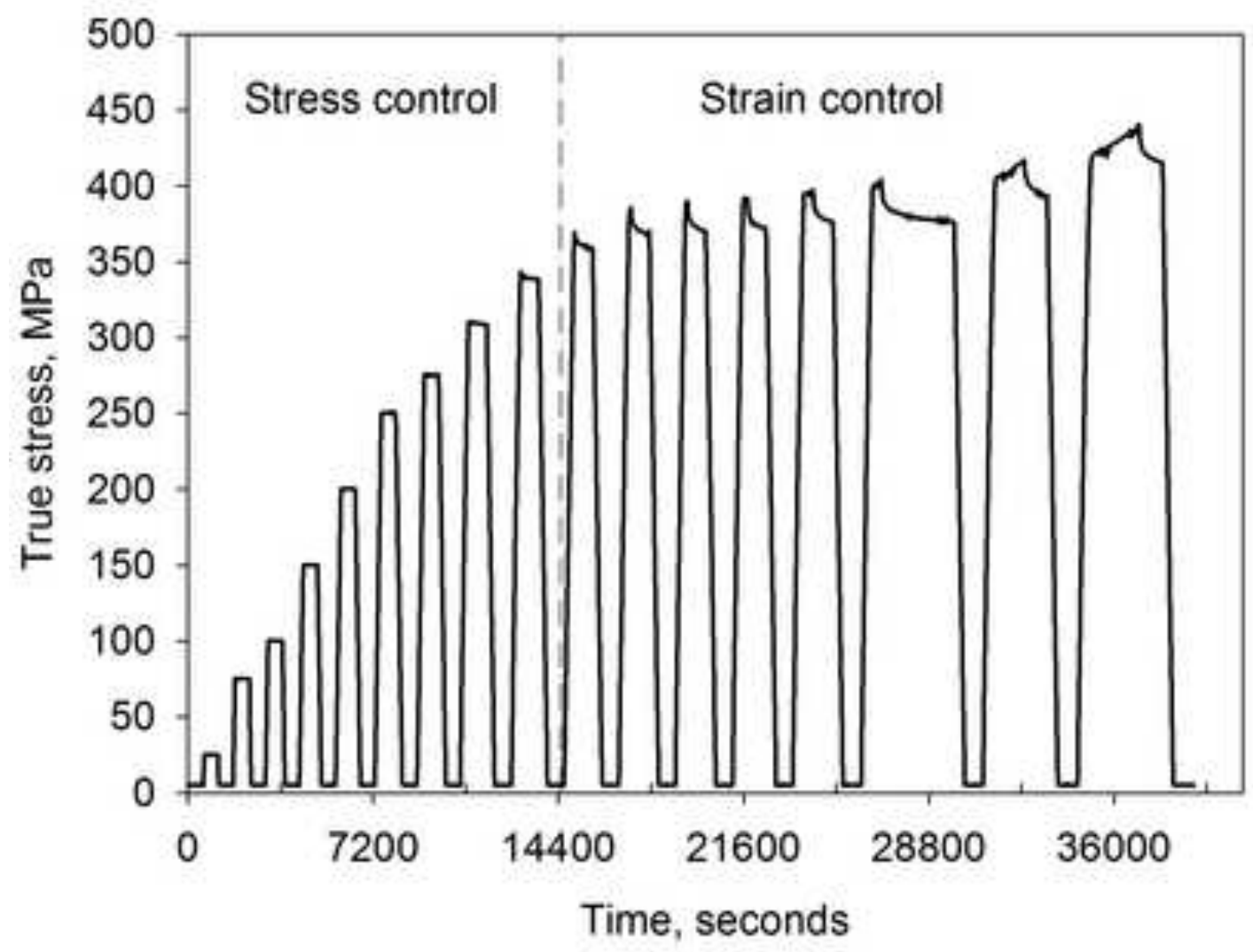

(a)

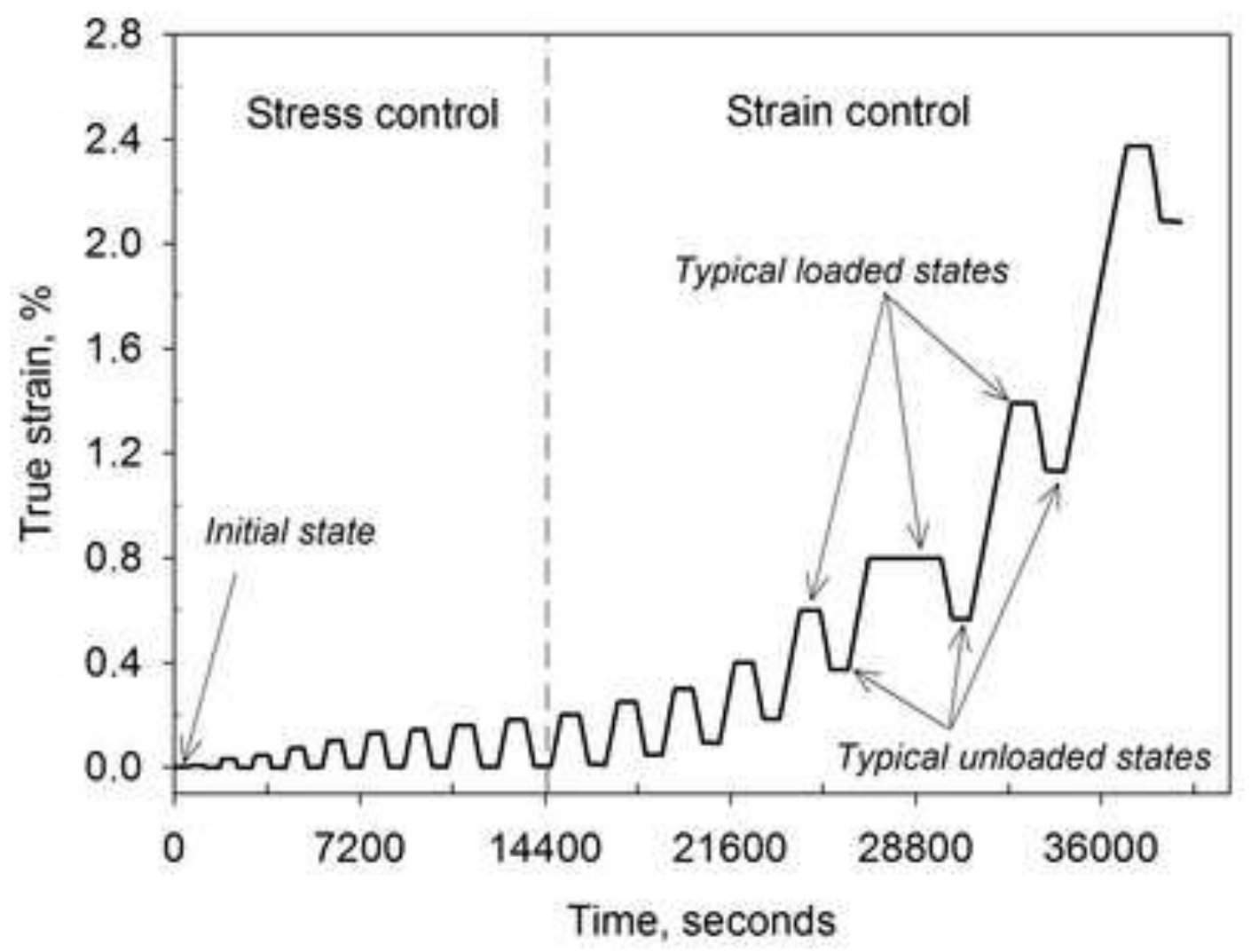

(b) 


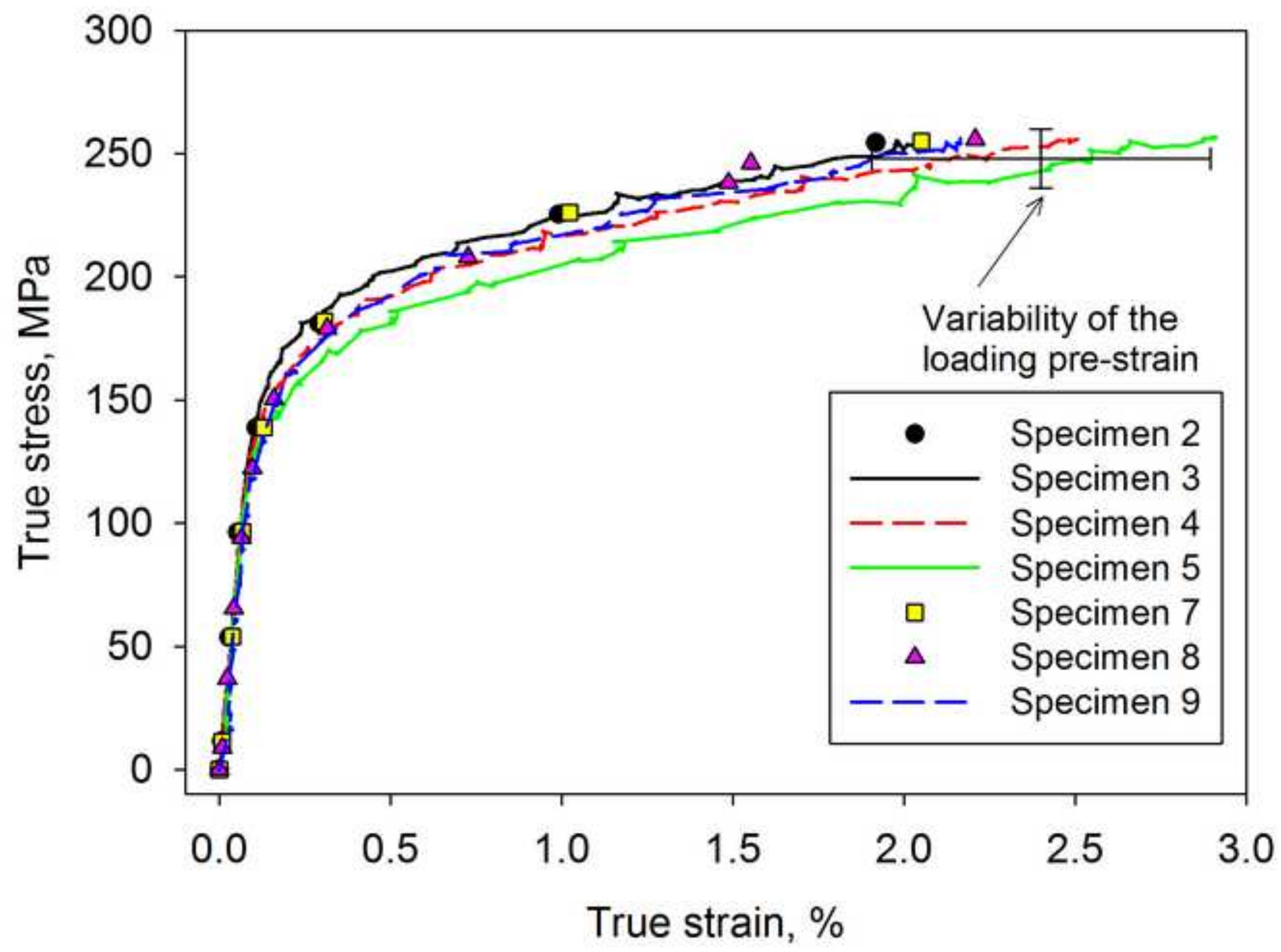




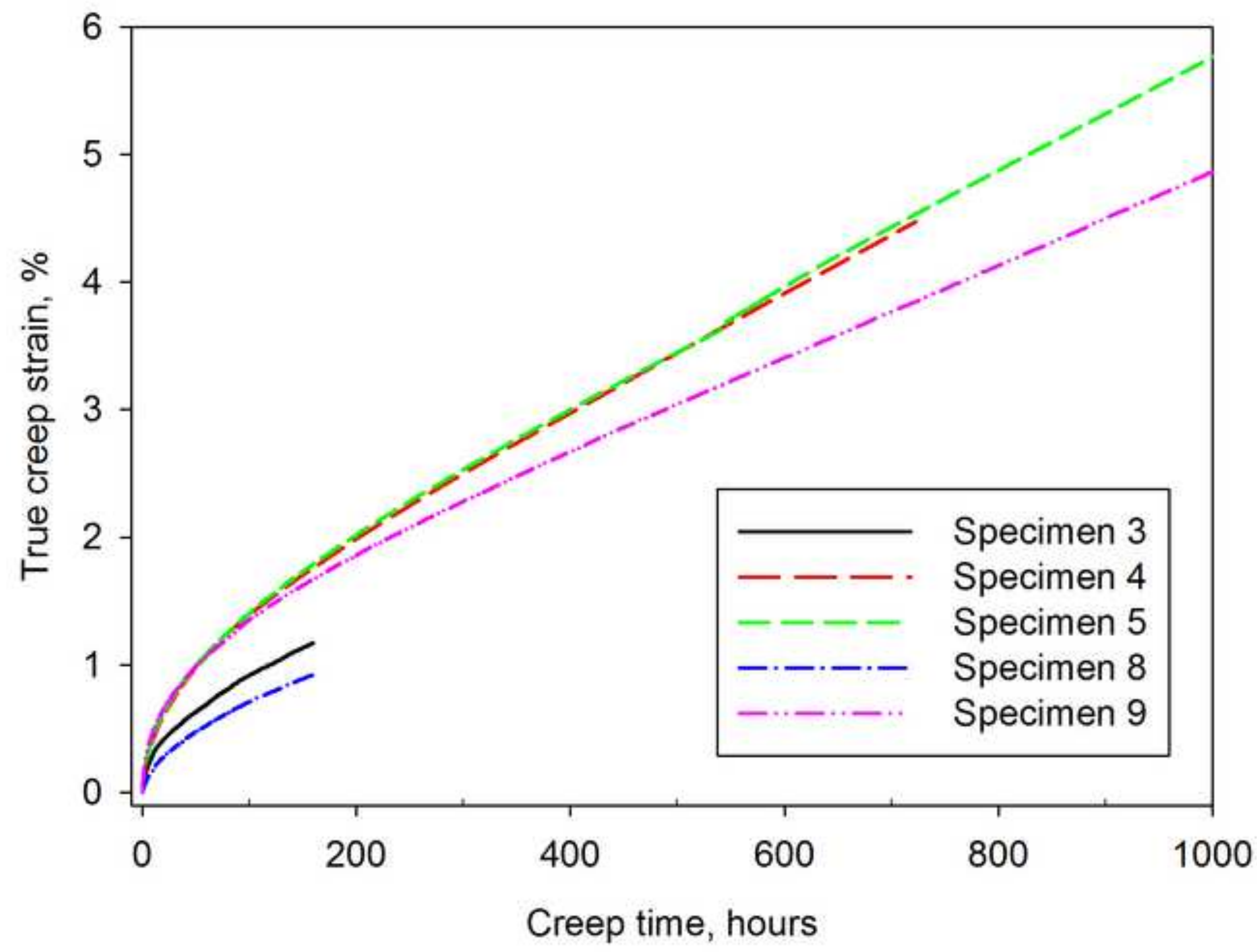




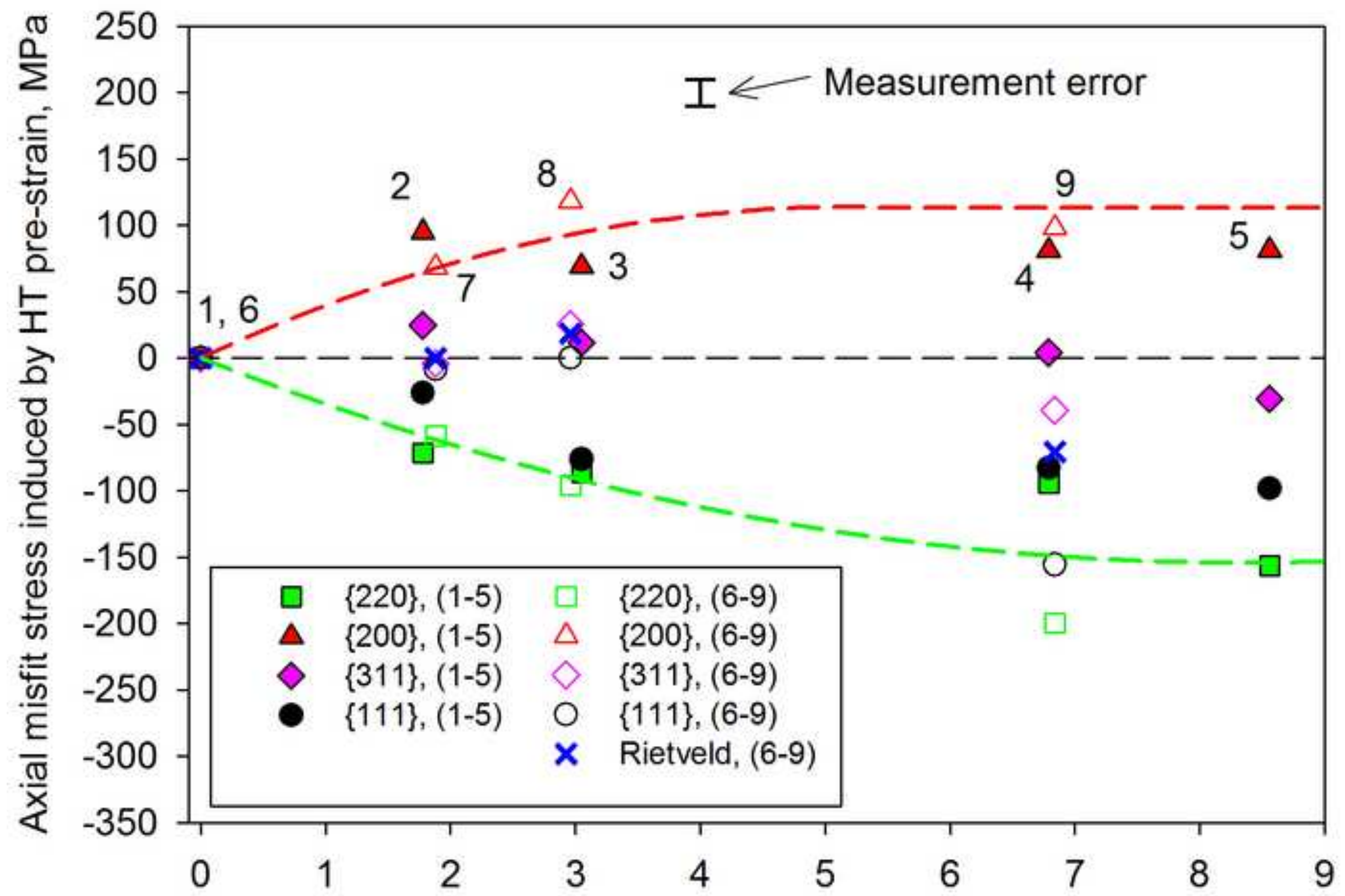

Total inelastic strain induced by HT pre-strain, \% 


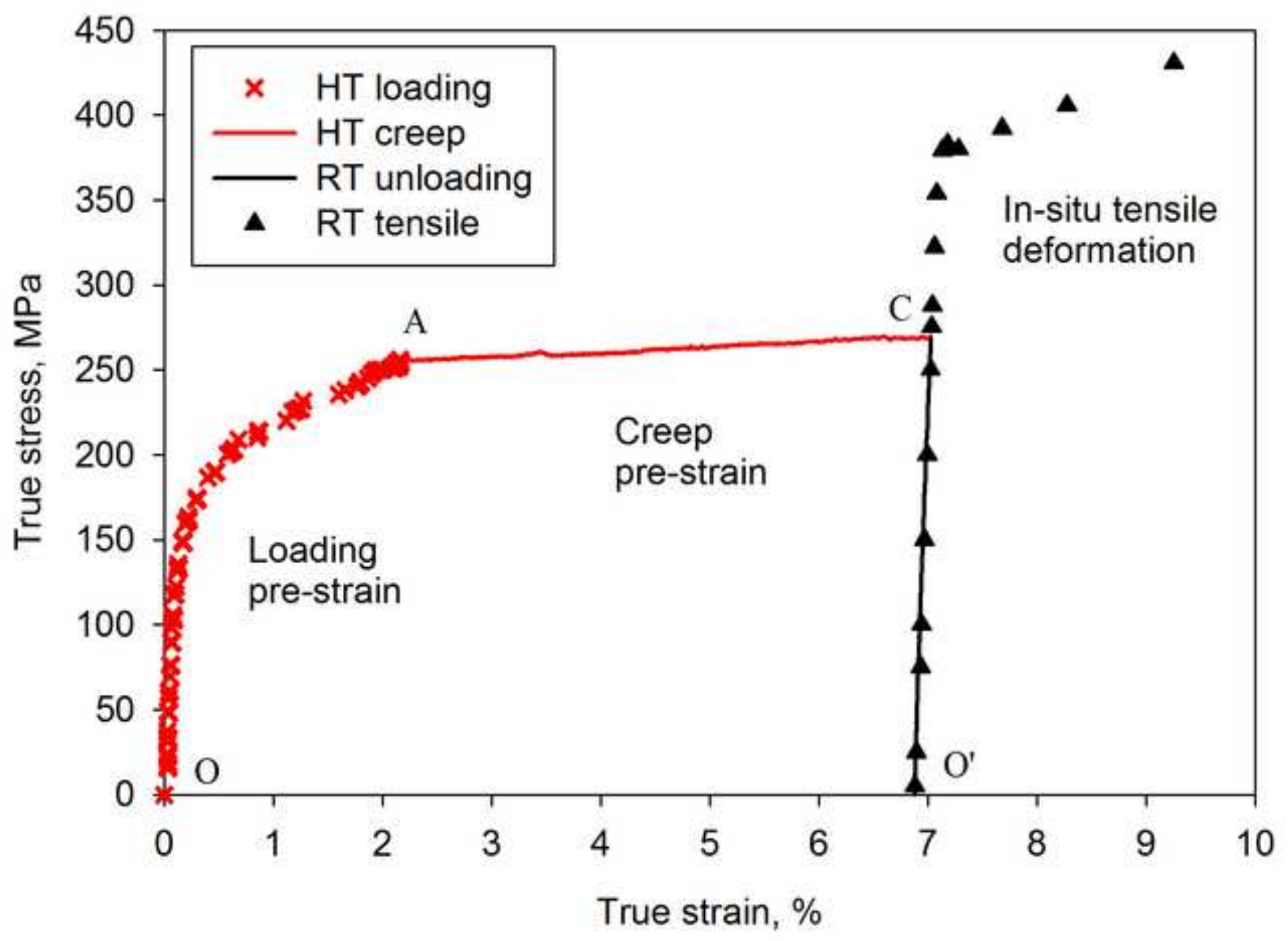


- $\bullet-$ No pre-strain, compressive (1) - $-\boxminus-$ Primary creep, compressive (3)

$\longrightarrow$ No pre-strain, tensile (6)

$\square-$ Primary creep, tensile (8)

- $\triangle$ - Loaded, compressive (2)

$-\nabla-$ Secondary creep, compressive (4)

$\triangle \sim$ Loaded, tensile (7)

$\rightarrow-$ Secondary creep, tensile (9)

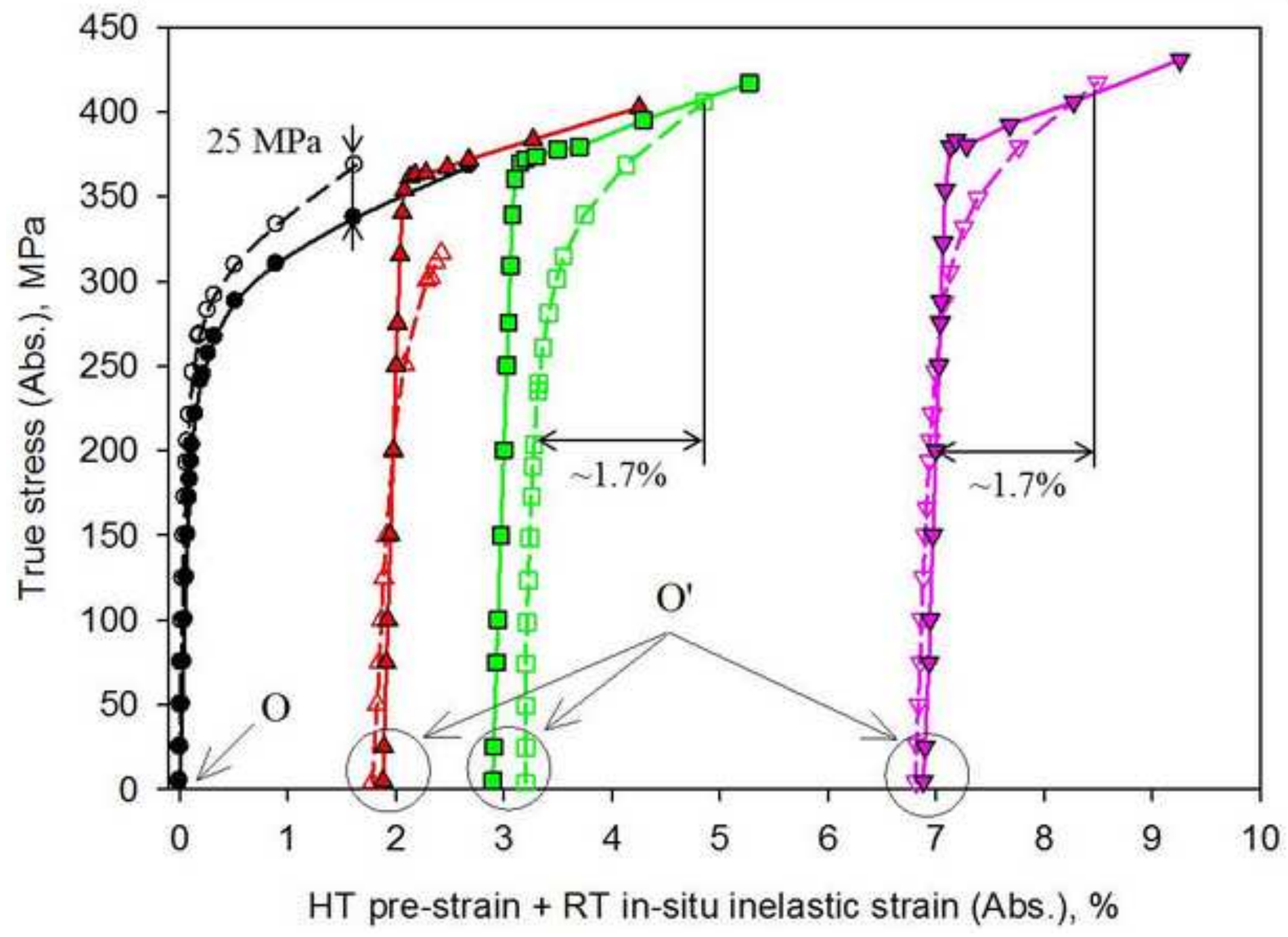




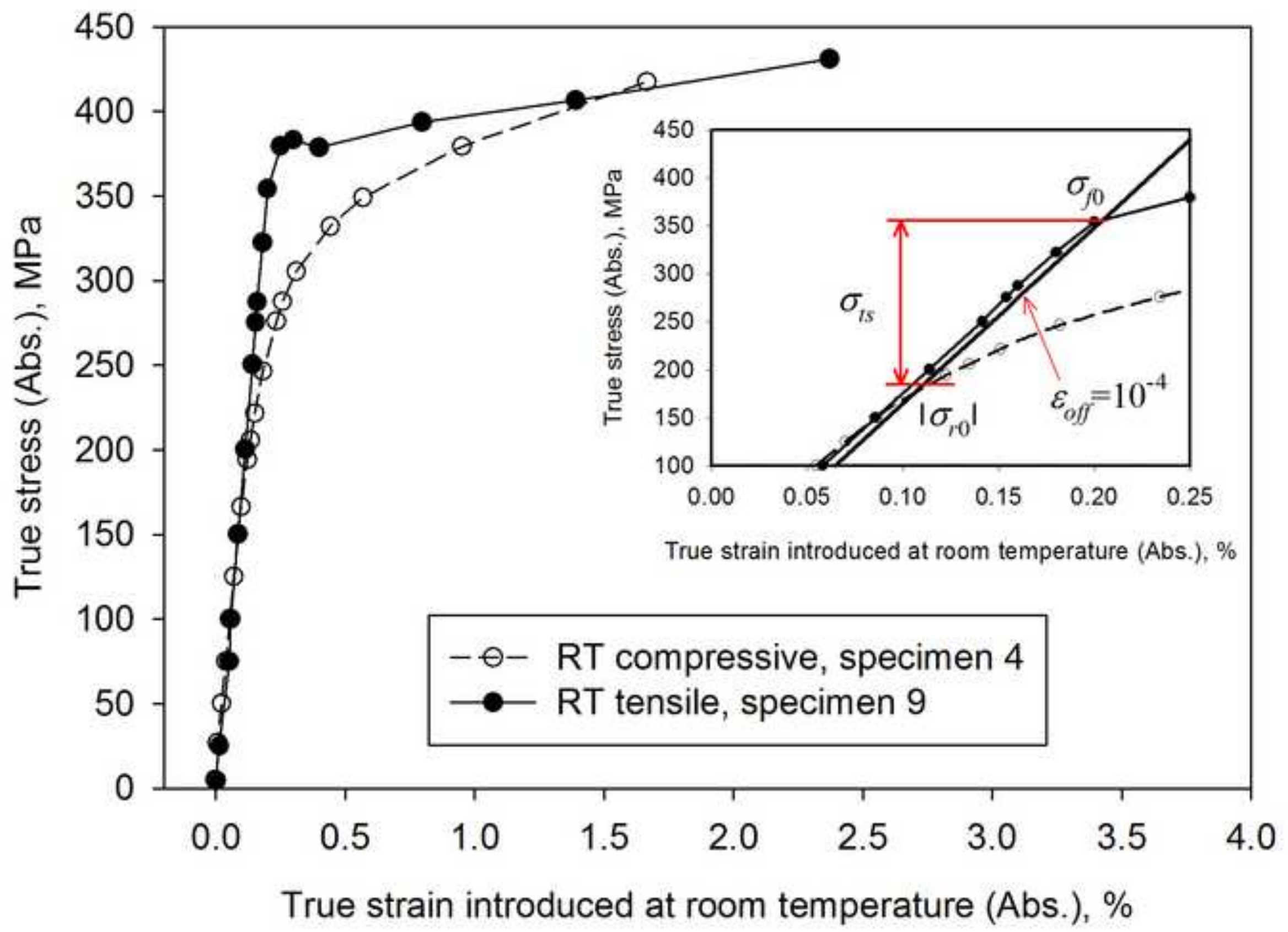




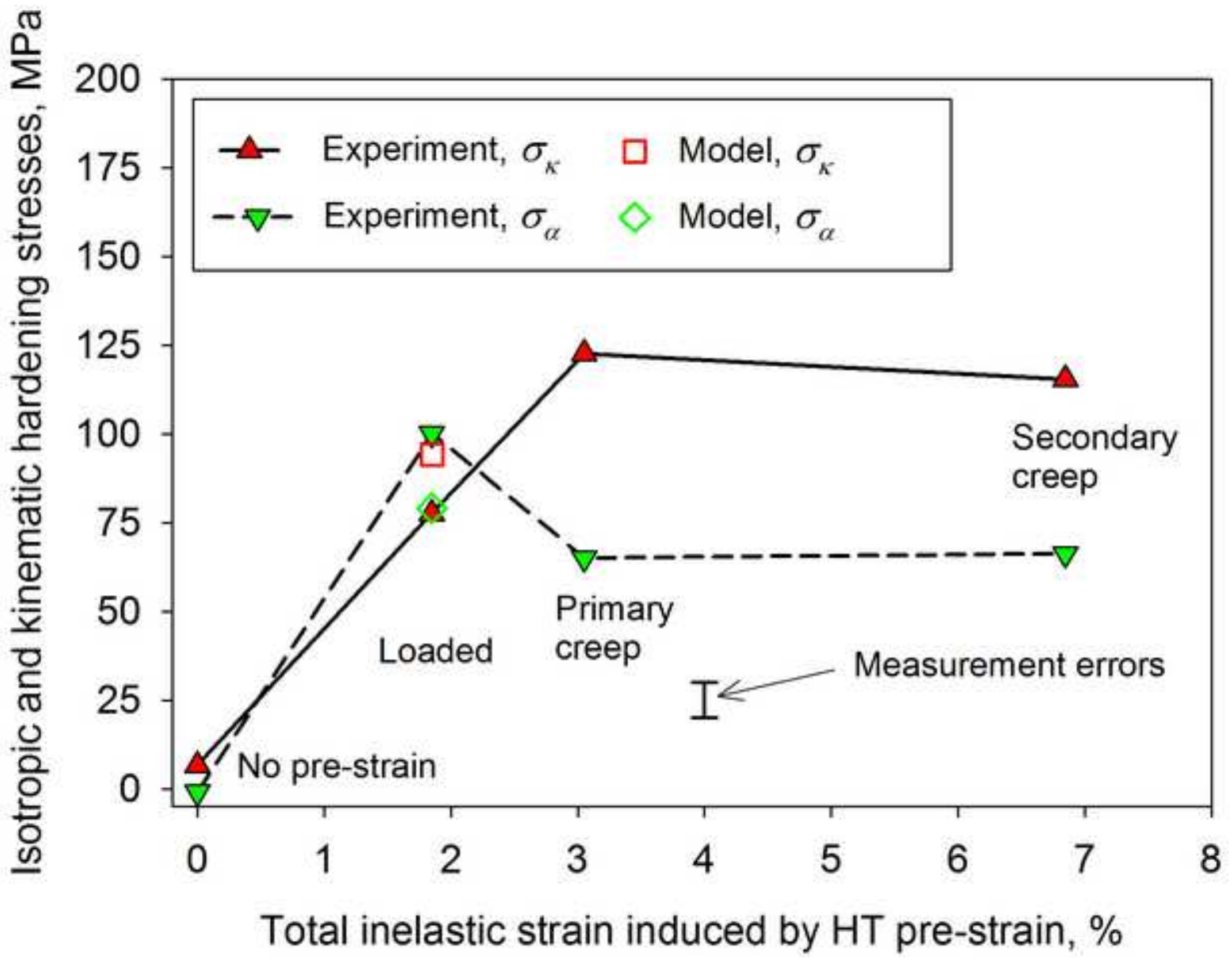




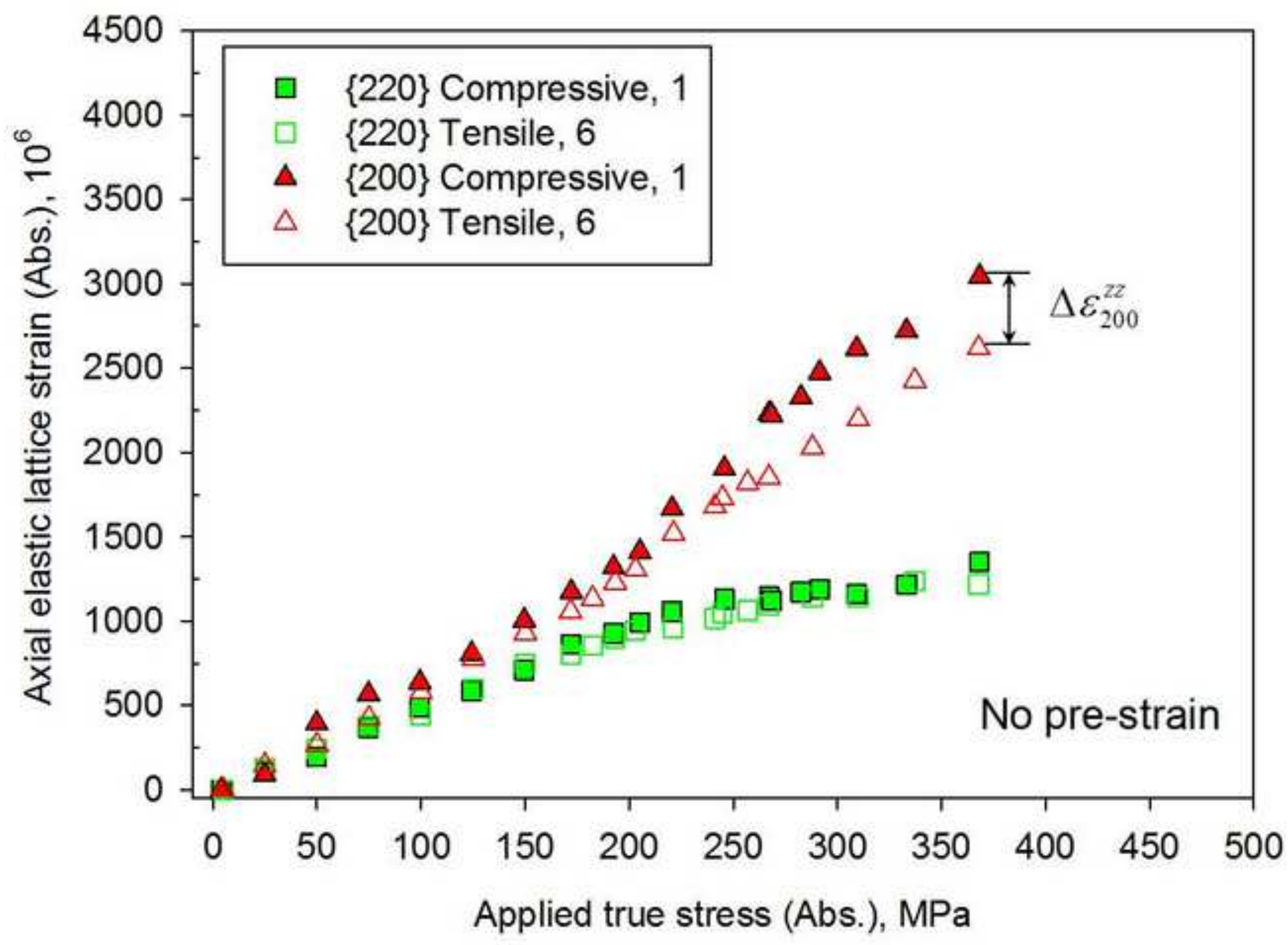

(a) 


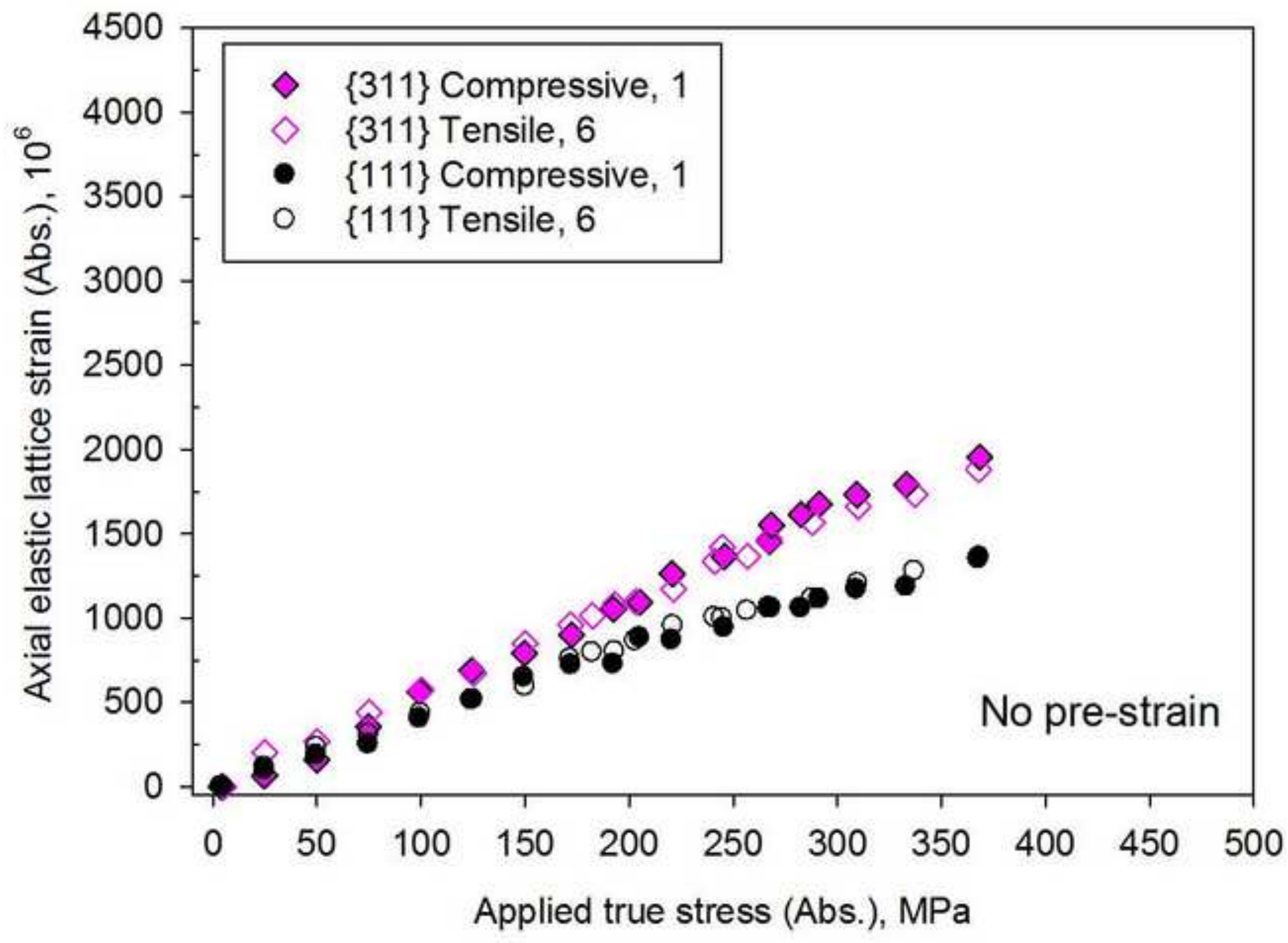

(b) 


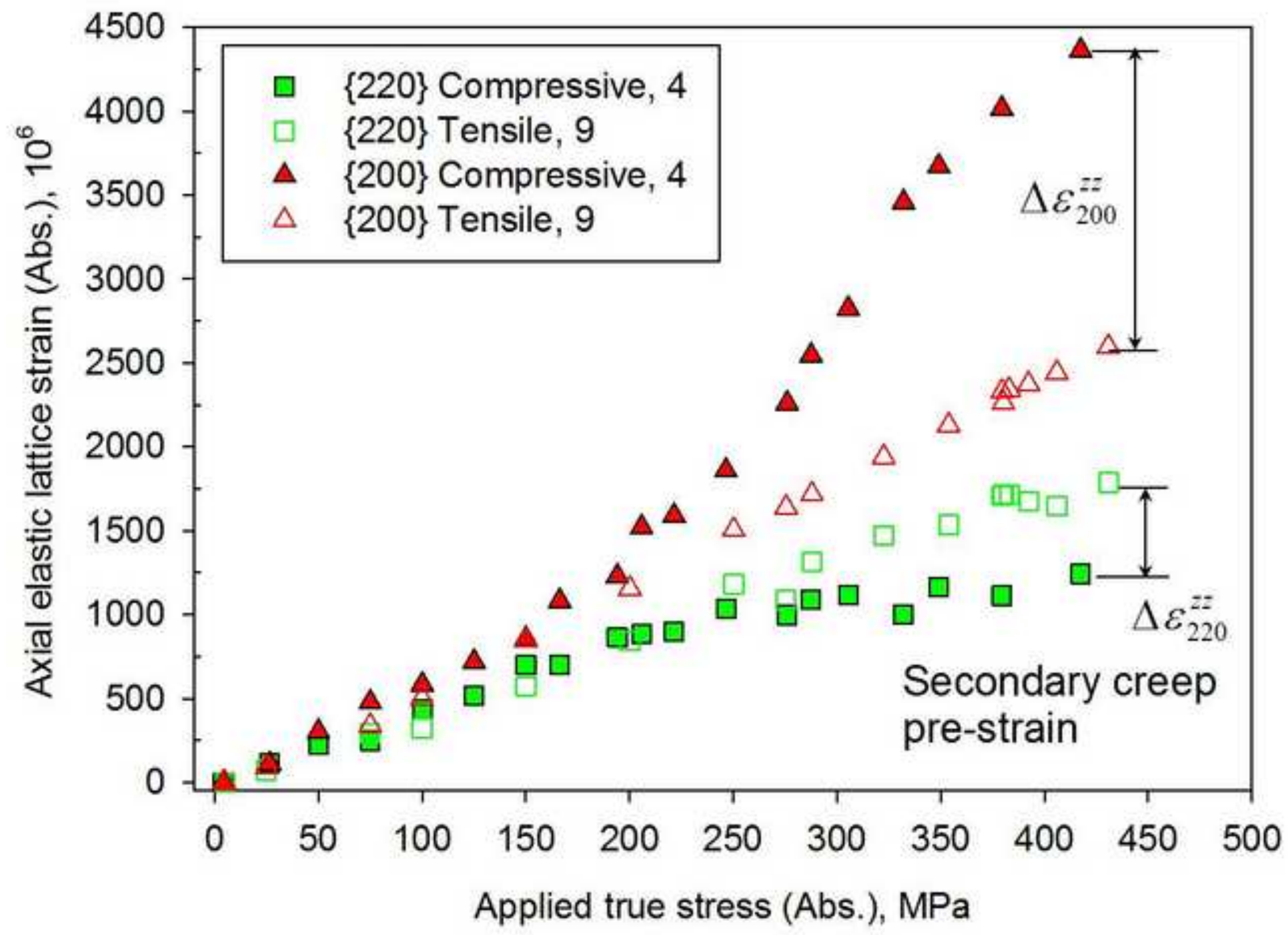

(c) 


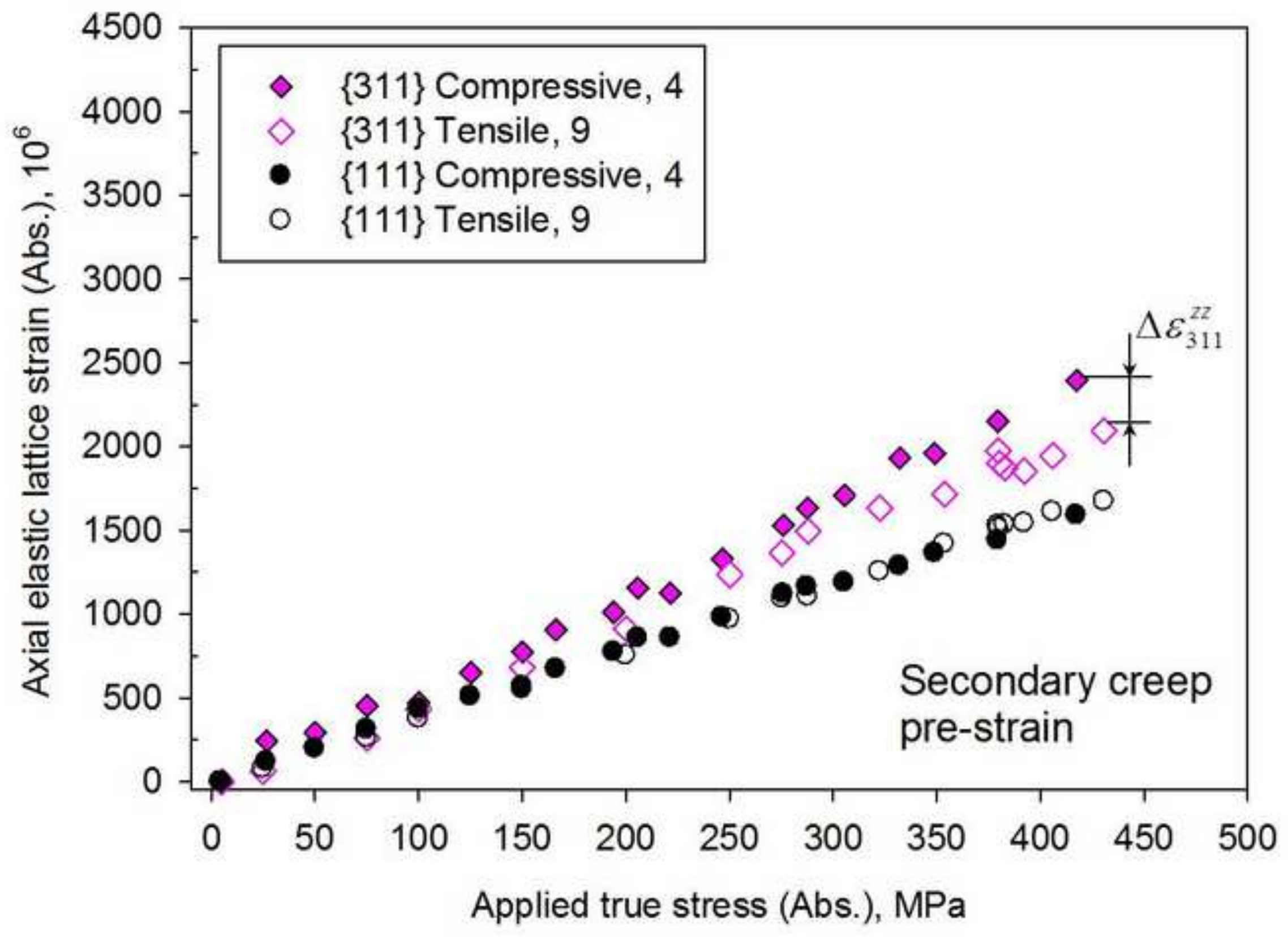

(d) 


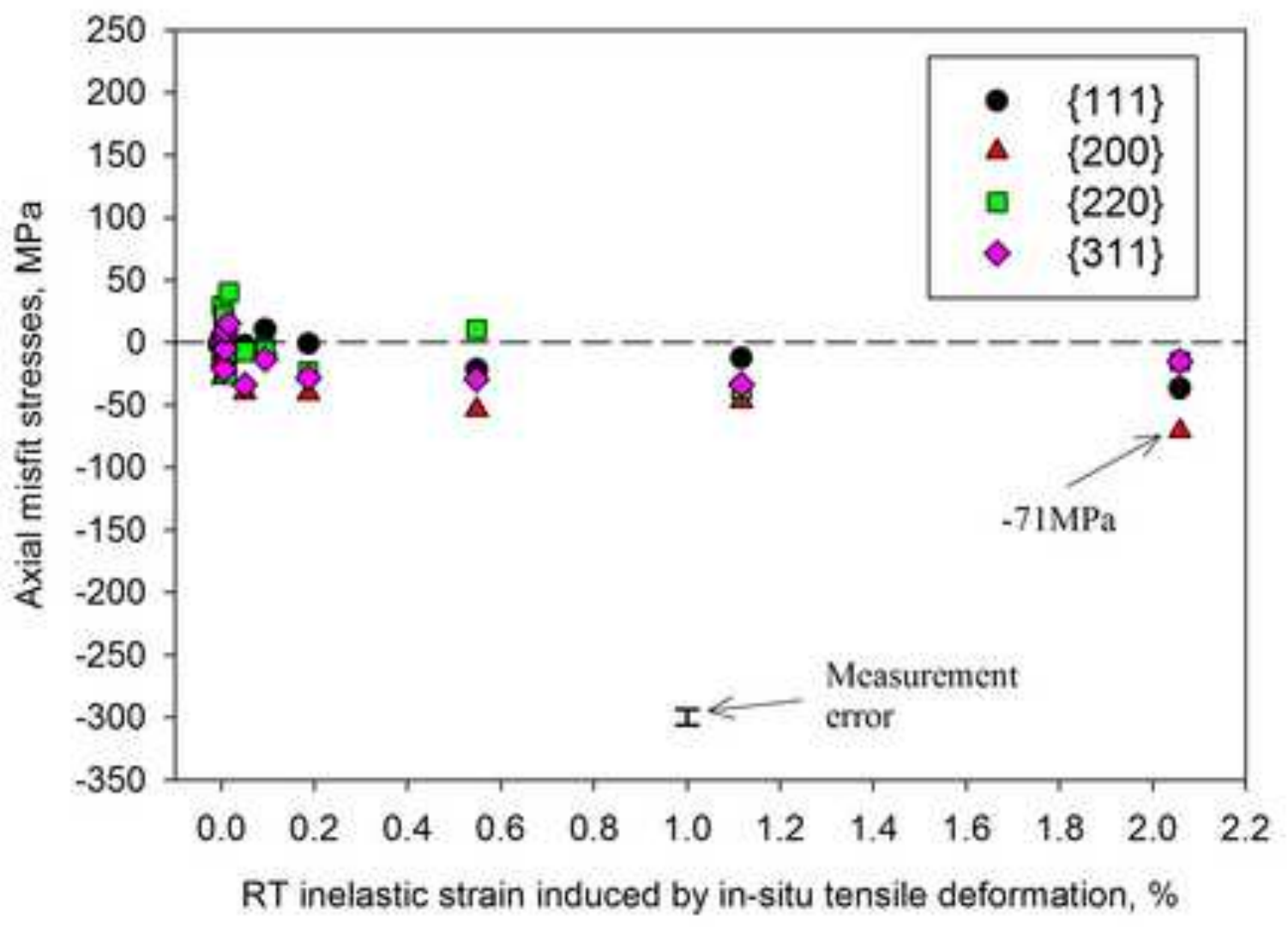

(a)

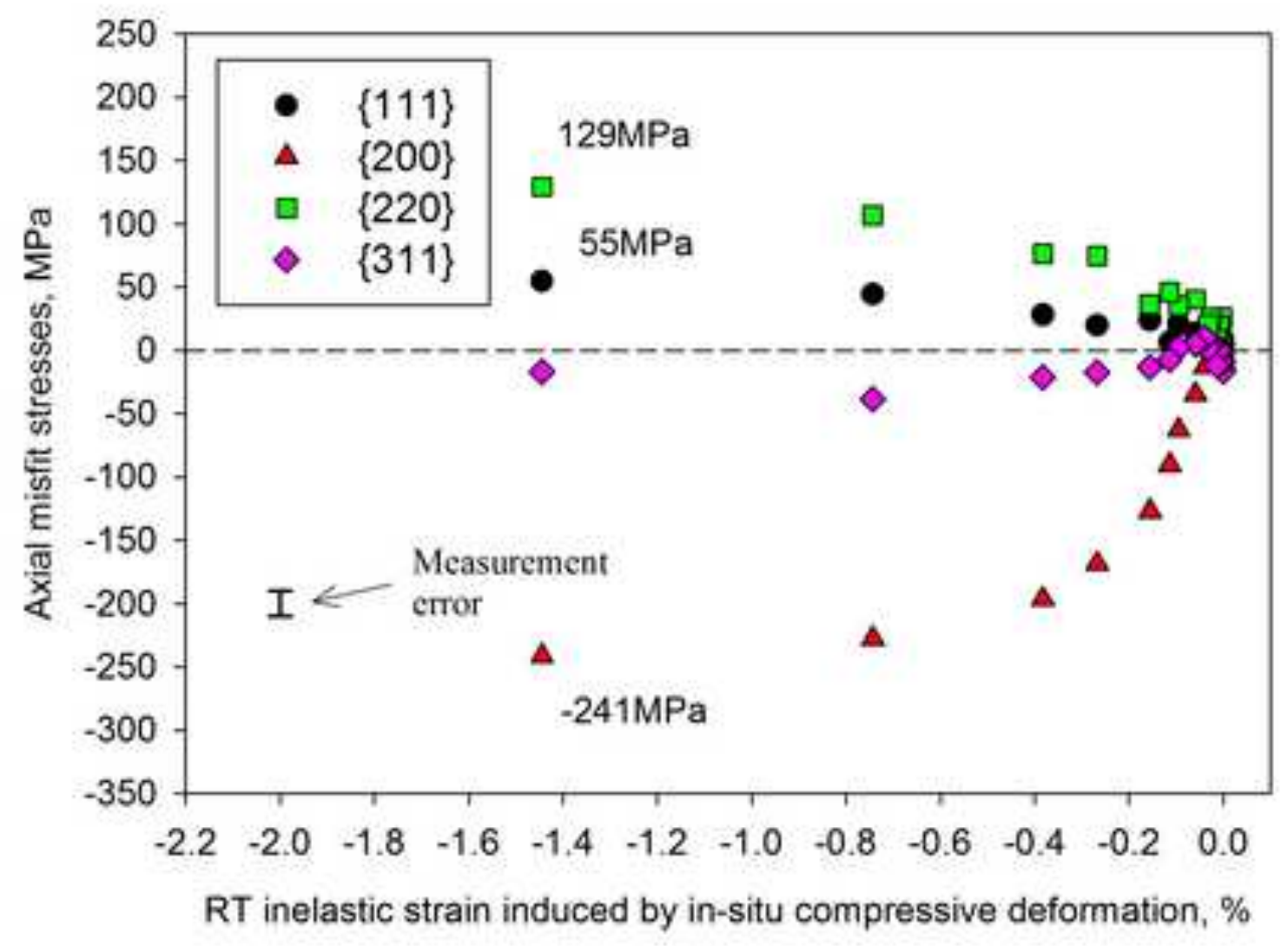

(b) 


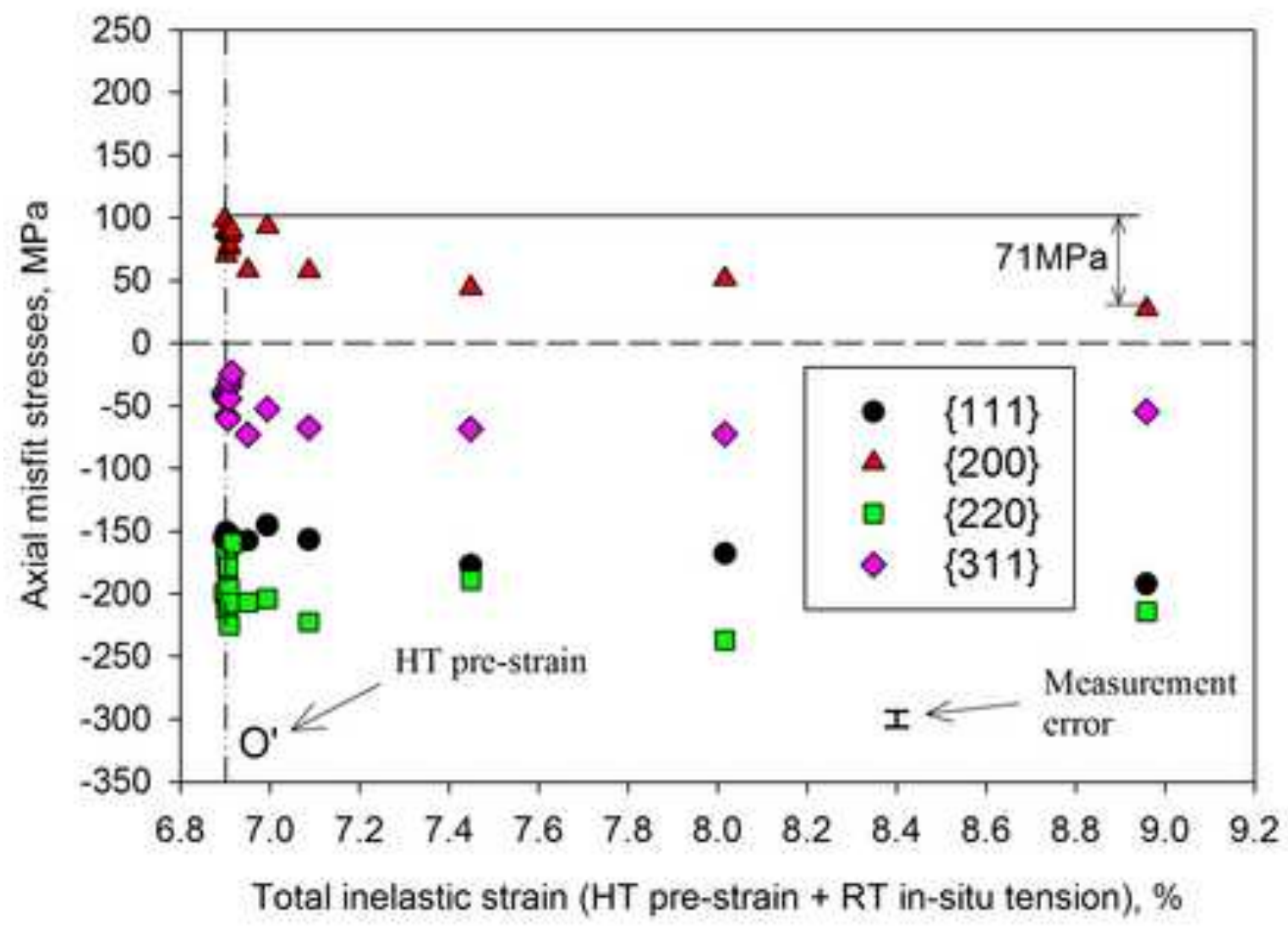

(a)

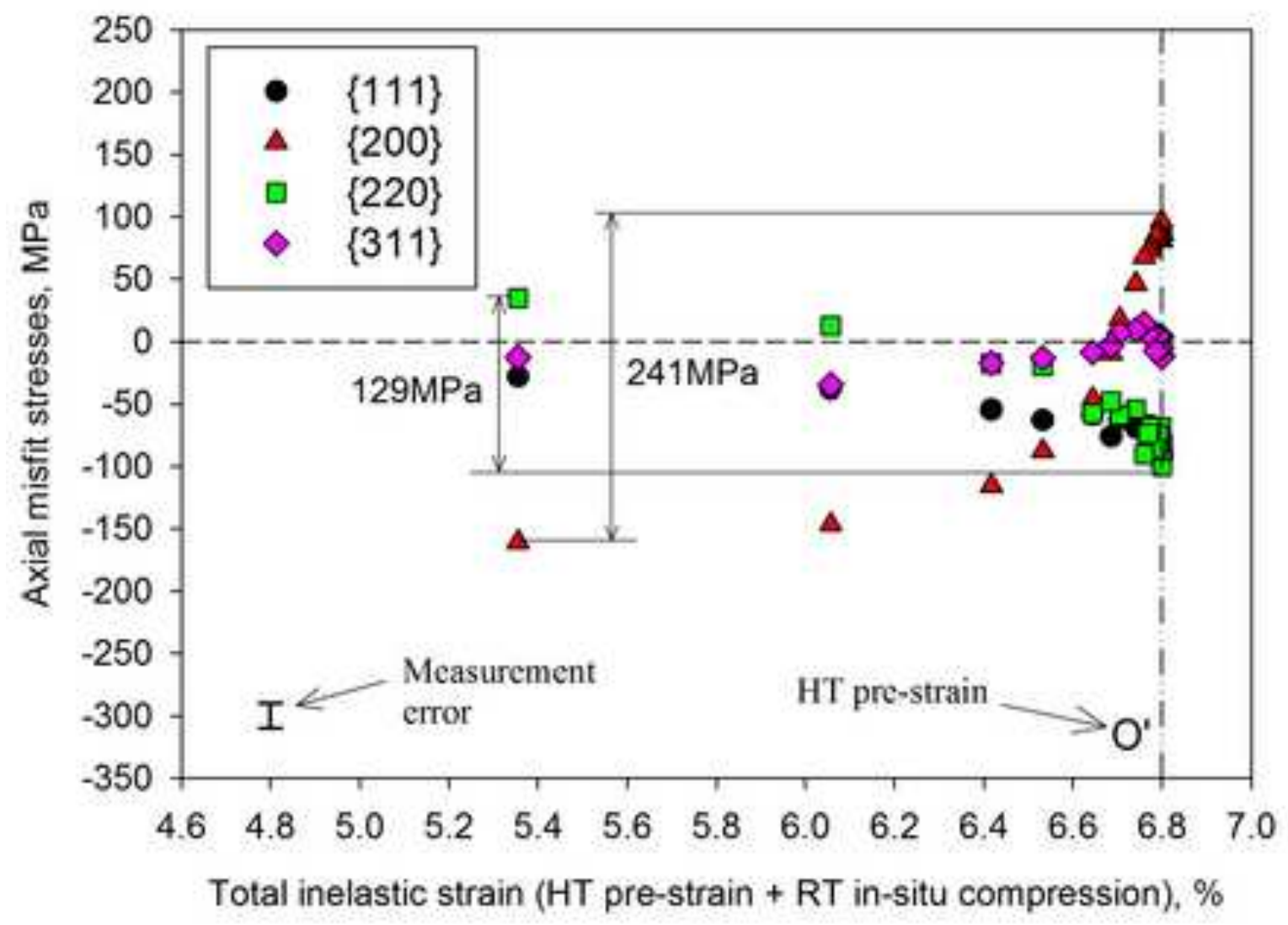

(b) 


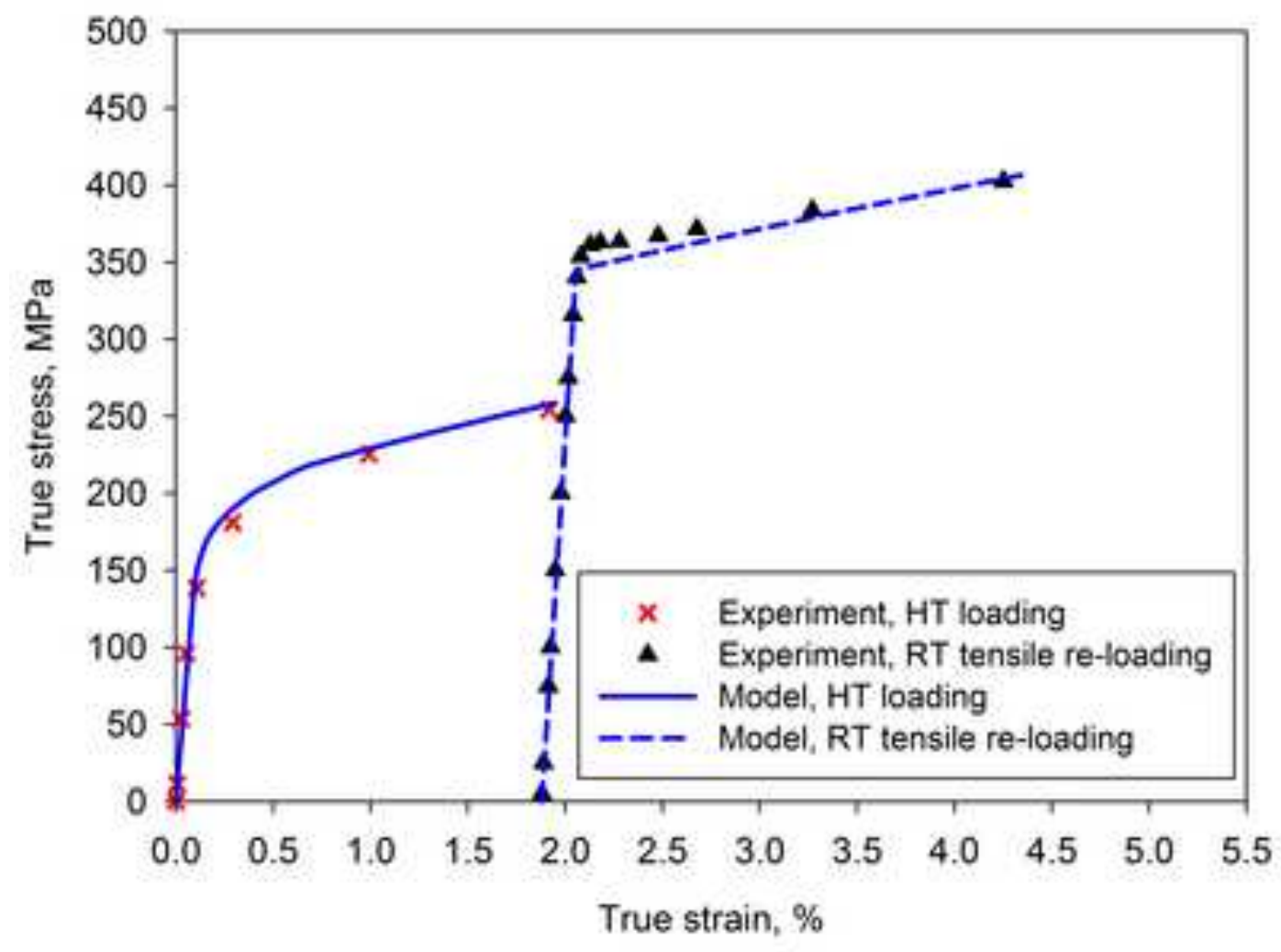

(a)

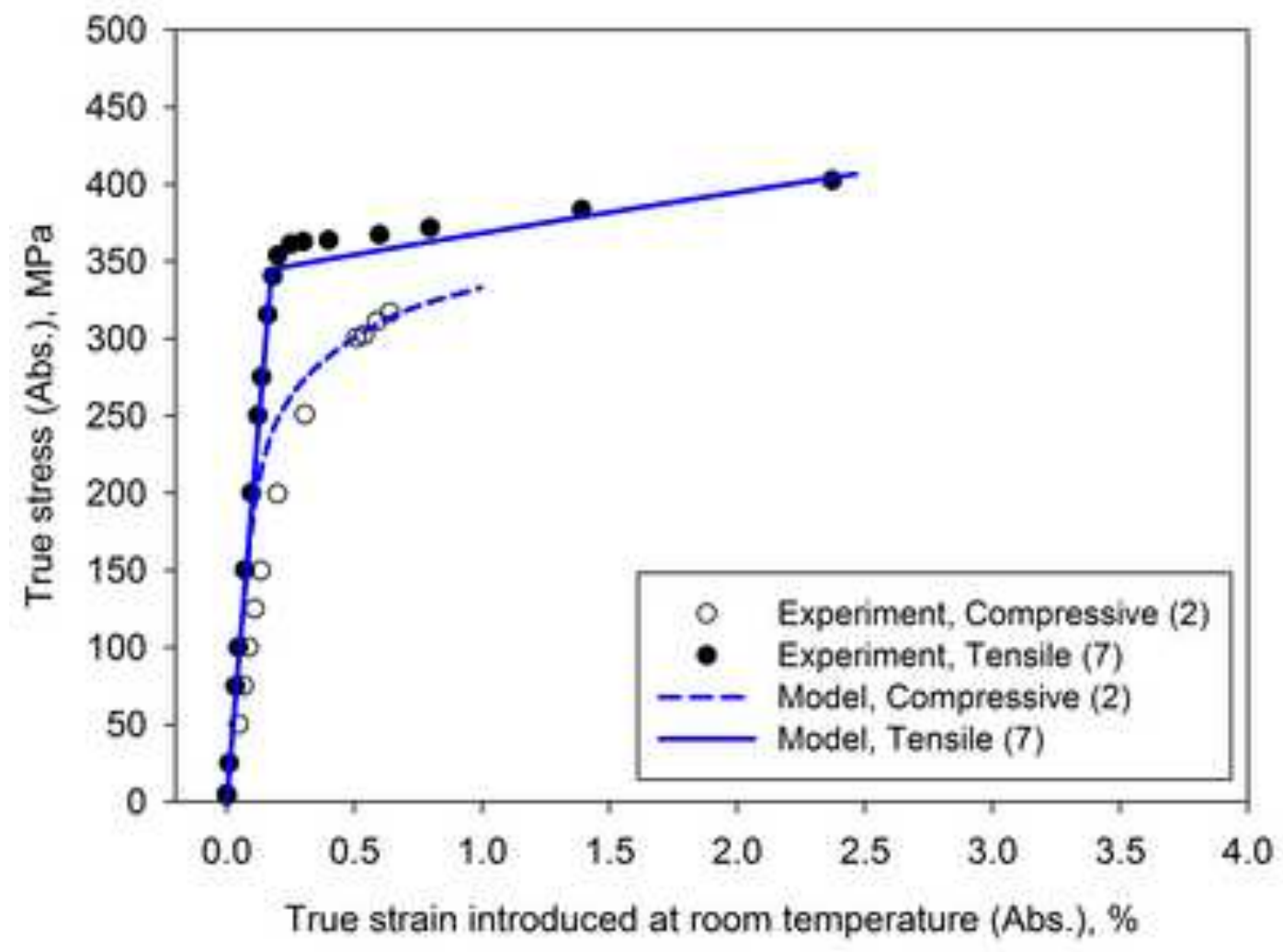

(b) 


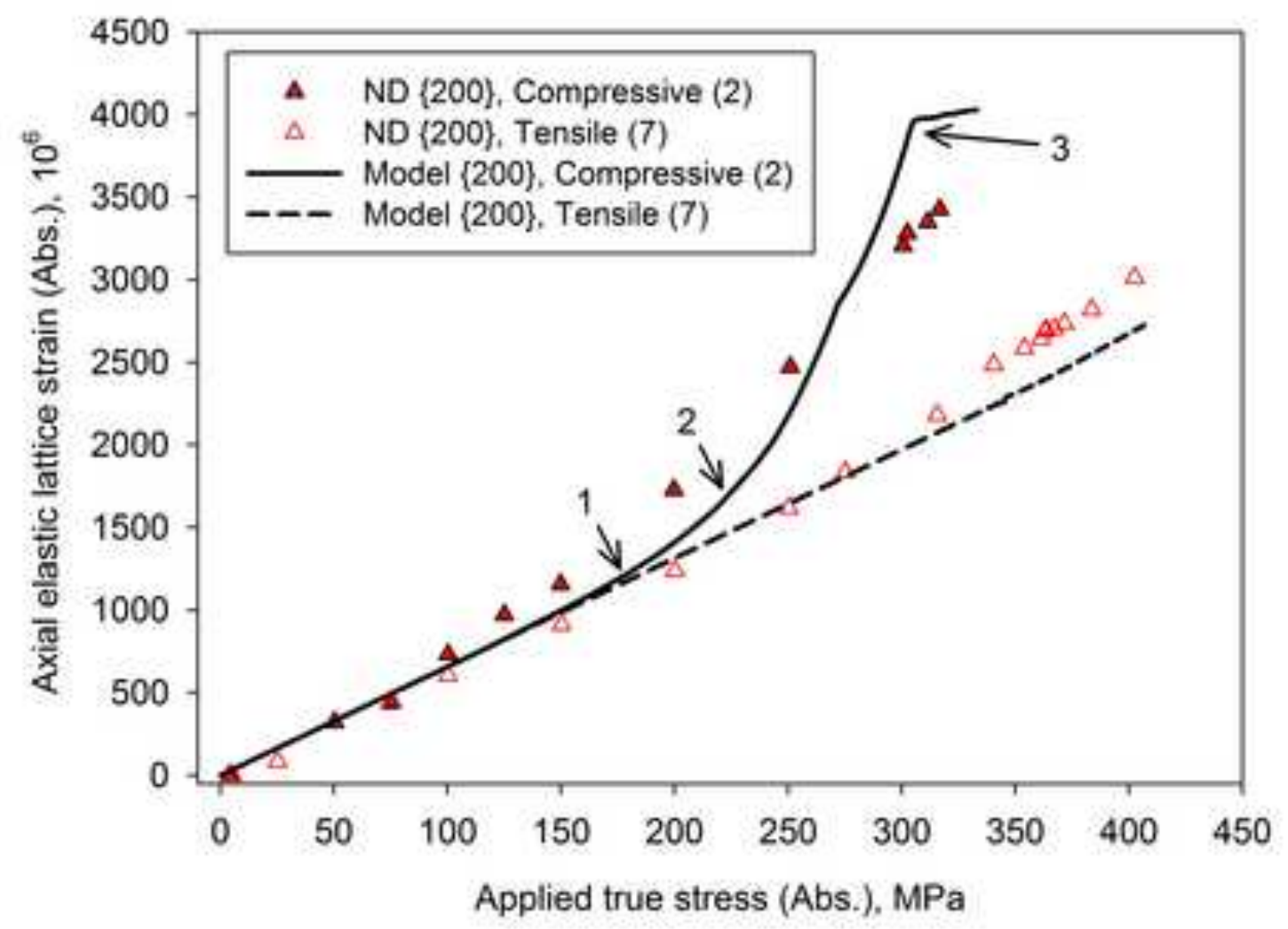

(a)

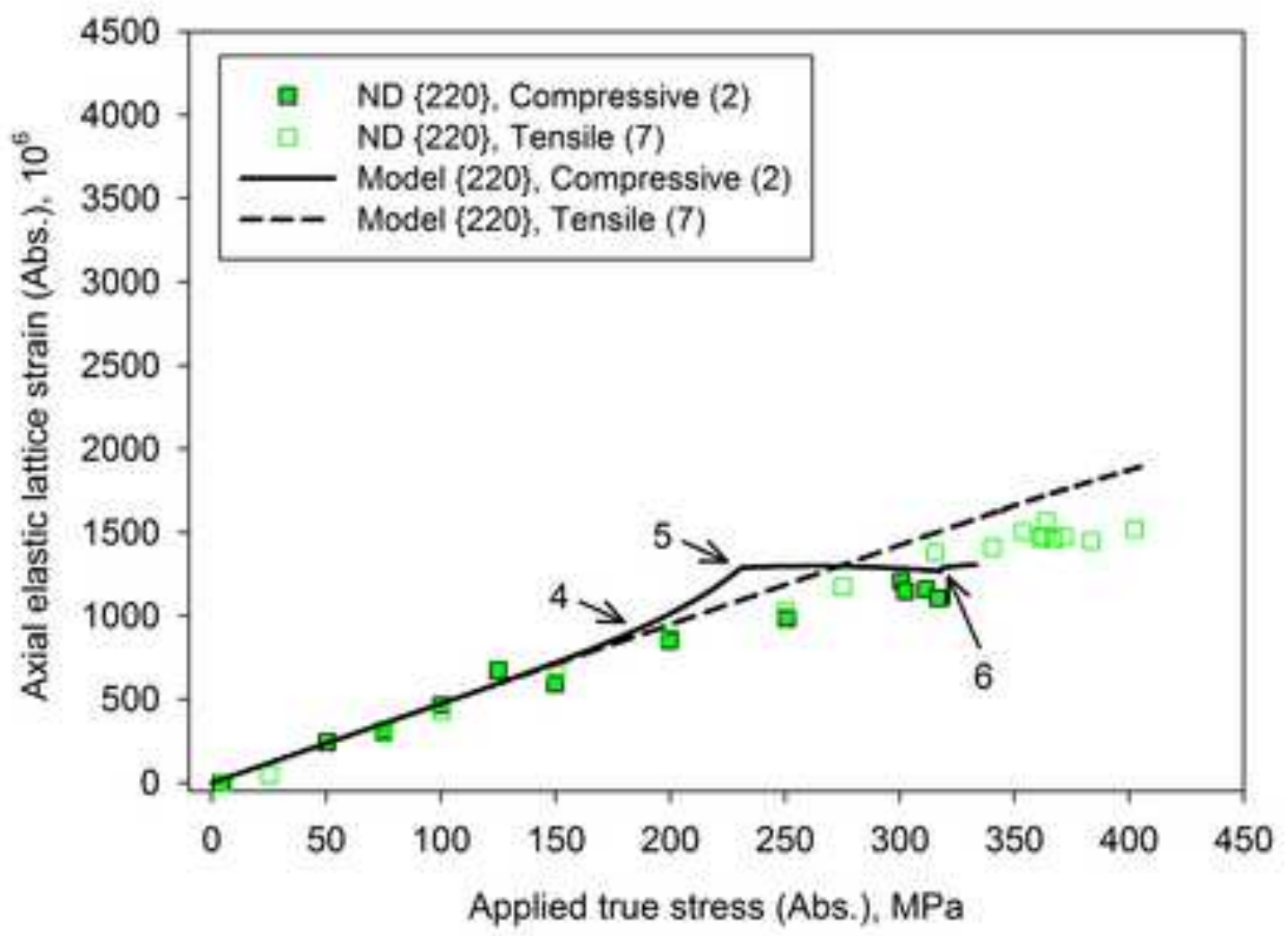

(b) 


\section{Tables}

Table 1. Chemical composition (wt.\%) of Type $316 \mathrm{H}$ stainless steel

\begin{tabular}{ccccccccccc}
\hline $\mathrm{C}$ & $\mathrm{Si}$ & $\mathrm{Mn}$ & $\mathrm{P}$ & $\mathrm{S}$ & $\mathrm{Cr}$ & $\mathrm{Mo}$ & $\mathrm{Ni}$ & $\mathrm{Co}$ & $\mathrm{B}$ & $\mathrm{Fe}$ \\
\hline 0.06 & 0.4 & 1.98 & 0.021 & 0.014 & 17.17 & 2.19 & 11.83 & 0.10 & 0.005 & Bal. \\
\hline
\end{tabular}

Table 2. Summary of Type $316 \mathrm{H}$ austenitic stainless steel specimens subjected to deformation at room temperature combined with in-situ neutron diffraction measurements. Specimens 2 to 5 and 7 to 9 were pre-strained at an applied tensile stress of 250MPa prior to room temperature deformation.

\begin{tabular}{|c|c|c|c|c|c|c|}
\hline $\begin{array}{c}\text { Specimen } \\
\text { ID }\end{array}$ & $\begin{array}{c}\text { Pre-strain } \\
\left(550^{\circ} \mathrm{C}\right)\end{array}$ & $\begin{array}{c}\text { Plastic } \\
\text { loading } \\
\text { strain, \% }\end{array}$ & $\begin{array}{c}\text { Creep } \\
\text { strain, } \\
\%\end{array}$ & $\begin{array}{c}\text { Total } \\
\text { inelastic } \\
\text { strain, \% }\end{array}$ & $\begin{array}{c}\text { In-situ } \\
\text { deformation }\end{array}$ & $\begin{array}{l}\text { Neutron } \\
\text { source }\end{array}$ \\
\hline 1 & $\begin{array}{l}\text { No pre- } \\
\text { strain }\end{array}$ & 0 & 0 & 0 & Compression & \multirow{5}{*}{ POLDI } \\
\hline 2 & Loaded & 1.8 & 0 & 1.8 & Compression & \\
\hline 3 & Creep 160h & 2.0 & 1.2 & 3.2 & Compression & \\
\hline 4 & Creep 720h & 2.3 & 4.5 & 6.8 & Compression & \\
\hline 5 & Creep 1000h & 2.7 & 5.8 & 8.5 & Tension & \\
\hline 6 & $\begin{array}{l}\text { No pre- } \\
\text { strain }\end{array}$ & 0 & 0 & 0 & Tension & \multirow{4}{*}{ ENGIN-X } \\
\hline 7 & Loaded & 1.9 & 0 & 1.9 & Tension & \\
\hline 8 & Creep 160h & 2.0 & 0.9 & 2.9 & Tension & \\
\hline 9 & Creep 1000h & 2.0 & 4.9 & 6.9 & Tension & \\
\hline
\end{tabular}


Table 3. Summary of the neutron diffraction measured changes of the misfit stresses during in-situ room temperature deformation of high temperature pre-strained and non-pre-strained specimens. RT: room temperature; HT: high temperature. Note: the total inelastic strain induced by high temperature prestrain for each specimen has been given in Table 2 .

\begin{tabular}{|c|c|c|c|c|c|c|}
\hline \multirow[t]{2}{*}{$\begin{array}{l}\text { Specimen } \\
\text { ID }\end{array}$} & \multirow{2}{*}{$\begin{array}{l}\text { Pre-strain at } 550^{\circ} \mathrm{C} \\
\text { (total HT inelastic } \\
\text { strain, \%) }\end{array}$} & \multirow{2}{*}{$\begin{array}{c}\text { RT } \\
\text { inelastic } \\
\text { strain, \% }\end{array}$} & \multicolumn{4}{|c|}{$\begin{array}{l}\text { Changes of the misfit stresses (absolute } \\
\text { values) during RT deformation }\end{array}$} \\
\hline & & & $\{200\}$ & $\{220\}$ & $\{111\}$ & $\{311\}$ \\
\hline 1 & No pre-strain $(0)$ & -1.4 & 81 & 57 & 30 & 2 \\
\hline 2 & Loaded (1.8) & -0.5 & 199 & 85 & 5 & 39 \\
\hline 3 & Creep 160h (3.2) & -1.4 & 204 & 111 & 27 & 30 \\
\hline 4 & Creep 720h (6.8) & -1.4 & 241 & 129 & 55 & 17 \\
\hline 5 & Creep 1000h (8.5) & 1.4 & 14 & 24 & 27 & 46 \\
\hline 6 & No pre-strain $(0)$ & 1.6 & 81 & 63 & 7 & 24 \\
\hline 7 & Loaded (1.9) & 2.1 & 50 & 47 & 43 & 33 \\
\hline 8 & Creep 160h (2.9) & 2.1 & 7 & 29 & 70 & 28 \\
\hline 9 & Creep 1000h (6.9) & 2.1 & 71 & 15 & 37 & 15 \\
\hline
\end{tabular}

